Nat. Hazards Earth Syst. Sci., 20, 1391-1414, 2020

https://doi.org/10.5194/nhess-20-1391-2020

(C) Author(s) 2020. This work is distributed under

the Creative Commons Attribution 4.0 License.

\title{
A multi-hazard risk prioritisation framework for cultural heritage assets
}

\author{
Giacomo Sevieri $^{1}$, Carmine Galasso ${ }^{1,2}$, Dina D'Ayala ${ }^{1}$, Richard De Jesus ${ }^{3}$, Andres Oreta ${ }^{3}$, Mary Earl Daryl A. Grio ${ }^{4}$, \\ and Rhodella Ibabao 5 \\ ${ }^{1}$ Department of Civil, Environmental and Geomatic Engineering, University College London, London, UK \\ ${ }^{2}$ Scuola Universitaria Superiore (IUSS) Pavia, Pavia, Italy \\ ${ }^{3}$ Department of Civil Engineering, De La Salle University, Manila, Philippines \\ ${ }^{4}$ Department of Civil Engineering, Central Philippine University, Iloilo City, Philippines \\ ${ }^{5}$ Department of Management, University of the Philippines Visayas, Iloilo City, Philippines
}

Correspondence: Giacomo Sevieri (g.sevieri@ucl.ac.uk)

Received: 9 January 2020 - Discussion started: 17 January 2020

Revised: 10 April 2020 - Accepted: 14 April 2020 - Published: 20 May 2020

\begin{abstract}
Multi-hazard risk assessment of building portfolios is of primary importance in natural-hazard-prone regions, particularly for the prioritisation of disaster risk reduction and resilience-enhancing strategies. In this context, cultural heritage assets require special consideration because of their high vulnerability to natural hazards - due to ageing and types of construction - and their strong links with communities from both an economic and a historical-sociocultural perspective. This paper introduces a multi-hazard risk prioritisation framework specifically developed for cultural heritage assets. The proposed framework relies on a multilevel rapid-visual-survey (RVS) form for the multi-hazard exposure data collection and risk prioritisation of case-study assets. Because of the multilevel architecture of the proposed RVS form, based on three levels of refinement and information, an increasing degree of accuracy can be achieved in the estimation of structural vulnerability and, ultimately, structural risk of the considered assets. At the lowest level of refinement, the collected data are used for the computation of seismic-risk and wind-risk prioritisation indices, specifically calibrated in this study for cultural heritage assets with various structural and non-structural features. The resulting indices are then combined into a unique multi-hazard risk prioritisation index in which the intangible value of cultural heritage assets is also considered. This is achieved by defining a score expressing the cultural significance of the asset. The analytic hierarchy process is extensively used throughout the study to reduce the subjectivity involved in the frame-
\end{abstract}

work, thus obtaining a simplified yet robust approach which can be adapted to different building typologies. The proposed framework is applied to 25 heritage buildings in Iloilo City, Philippines, for which innovative, non-invasive techniques and tools for improved surveying have also been tested. Thermal and omnidirectional cameras have helped in the collection of structural data, together with drones for the inspection of roofs. Results of the study are presented and critically discussed, highlighting advantages and drawbacks of the use of new technologies in this field.

\section{Introduction and motivations}

Probabilistic risk assessment of building portfolios in natural-hazard-prone regions is of paramount importance to defining prioritisation schemes for the design, implementation and optimisation of disaster risk reduction (DRR) and resilience-enhancing strategies. This is even more important in developing countries, where most of the existing building stock has been designed and built according to obsolete codes (if any) and limited financial resources and coping capacities are available.

In this context, cultural heritage $(\mathrm{CH})$ assets require special consideration because of their physical vulnerability, which has been highlighted during recent catastrophic events (e.g. Fiorentino et al., 2018; World Bank Group, 2017) and their sociocultural value (e.g. European Commission, 2018). 
In fact, the lack of any hazard-resistant design (in most of the cases) and the presence of material degradation due to ageing, together with the possible presence of structural modifications and local repair and/or partial or total reconstructions over time, result in high levels of vulnerability characterising those assets (e.g. Despotaki et al., 2018; D’Ayala, 2014). In addition, assessing expected losses for a given set of hazard scenarios is a complex task because of the tangible and intangible values of $\mathrm{CH}$ assets (e.g. European Commission, 2018). The tangible value is mainly related to structural-architectural characteristics (direct losses), often hardly quantifiable due to the uniqueness of a given asset, and to the link with the economy of a region through cultural tourism (indirect losses). Moreover, $\mathrm{CH}$ has a symbolic value for a given community. The feeling of place and belonging of citizens and the sense of collective purpose are strongly linked to $\mathrm{CH}$ assets; their damage and partial or total collapse can have a huge impact on social cohesion, sustainable development and psychological wellbeing. These aspects provide $\mathrm{CH}$ assets with an intangible value, which must be somehow considered in the risk assessment at both a portfolio and a building-specific level. All these issues together make the quantification of $\mathrm{CH}$-asset exposure (i.e. the value at risk) a challenging task (e.g. European Commission, 2018).

An urgent need for integrating the specific features of $\mathrm{CH}$ assets into DRR plans has been recently highlighted by various national and international authorities across the world. One of the first published documents in this context is the report prepared by the World Heritage Committee (UNESCO, 2008), which stated that "most world heritage properties, particularly in developing areas of the world, do not have established policies, plans and processes for managing risk associated with potential disasters". In 2015 the UN General Assembly endorsed the Sendai Framework for Disaster Risk Reduction 2015-2030 (UNISDR, 2015) which, for the first time, explicitly included $\mathrm{CH}$ in the overall agenda of DRR. The framework clearly recognises culture as a key dimension of DRR, with $\mathrm{CH}$ specifically referred to under two priorities: (1) understanding disaster risk and (2) investing in DRR for resilience. However, the sector could also contribute significantly to priorities such as (3) enhancing disaster preparedness for effective response. These directions were transposed at a European level through the publication of the Action Plan on the Sendai Framework for Disaster Risk Reduction 2015-2030 (SWD, 2016), which promoted collaboration between the public (e.g. governments) and the private sector (e.g. engineering consultancies, (re)insurance companies) for the implementation of resilience-enhancing strategies for $\mathrm{CH}$ assets. Following this idea, for the first time, in 2018, an insurance company was instructed by the Italian Episcopal Conference (CEI) to provide a (re)insurance policy for religious buildings from natural catastrophe risks in all 25796 parishes of the 225 Italian dioceses, thus boosting the interest of (re)insurance companies and risk modellers in the CH-asset market (Sheehan, 2018).
Any DRR strategy, designed by governmental agencies or other stakeholders, should be based on a rational understanding of natural-hazard risks of large building stocks. However, performing detailed structural analyses for a large number of structures is not cost-effective because it would require highperformance computing and specific technical resources. Therefore, simplified methods for multi-hazard risk prioritisation and assessment of building portfolios (e.g. FEMA, 2015b), framed in multilevel frameworks (e.g. Moratti et al., 2019), represent essential tools to prioritise further detailed analyses and any DRR and/or resilience-enhancing intervention. Such simplified methods should allow an analyst to also account for the intangible value of $\mathrm{CH}$ assets and to consider their specific construction features by just using a small amount of information - to be typically collected in highly complex urban settings, such as in developing countries.

This paper addresses the above-mentioned issues by proposing a multilevel, multi-hazard risk assessment framework for $\mathrm{CH}$ assets, with a special focus on reinforced concrete (RC) frames and unreinforced masonry (URM) buildings. The proposed framework relies on an ad hoc rapidvisual-survey (RVS) form which can be used to gather information for different levels of analysis varying in refinement. At the lowest refinement level, the focus of this paper, it allows an analyst to compute risk prioritisation indices against various natural hazards. Specifically, seismic-risk and windrisk prioritisation indices for $\mathrm{CH}$ assets are proposed. They represent an extension of those developed within the INdonesia School Programme to Increase REsilience (INSPIRE; Gentile et al., 2019) and the Safer COmmunities through Safer SchOols (SCOSSO; D'Ayala et al., 2020) projects respectively. In particular, the INSPIRE seismic-risk prioritisation index is extended to the case of URM buildings by providing specific performance modifiers (Sect. 3.2) and calibrating their relative weights. In a similar way, the SCOSSO wind-risk prioritisation index is adapted for the specific characteristics of $\mathrm{CH}$-asset roofs (Sect. 3.3). A simplified approach for the combination of the two indices, which also allows for an explicit consideration of the intangible value of $\mathrm{CH}$ assets (reflecting the $\mathrm{CH}$-asset significance; Kerr, 2013), is also proposed (Sect. 3.4 and 3.5). Weights and scores used in this study are calibrated through the analytic hierarchy process (AHP; Saaty, 1980) in order to reduce the subjectivity involved in the framework.

The effectiveness of the proposed framework has been demonstrated during a field survey of $25 \mathrm{CH}$ assets in Iloilo City, Philippines. With a population of 447992 inhabitants and a $1.02 \%$ population annual growth rate, Iloilo City is one of the most highly urbanised cities of the south-eastern tip of Panay island in the Philippines (Philippine Statistics Authority, 2016). It is also the capital city of the province of Iloilo and an important heritage hub for tourism in the Philippines. The historic street Calle Real, located in the old downtown district of Iloilo City, is home to several fine examples of historic buildings constructed in the first half of the 20th century 
during the American colonisation (ICCHCC, 2010). Most of them were surveyed during the fieldwork. Being located in a cyclonic region with the West Panay fault (the nearest one) just $15 \mathrm{~km}$ away (Yu and Oreta, 2015), Iloilo City represents a perfect case study to test the proposed multi-hazard risk and resilience assessment framework.

The overall framework has been developed within the Cultural Heritage Resilience \& Sustainability to multiple Hazards (CHeRiSH) project, funded by the UK Newton Fund, which aims to define a multilevel risk and resilience assessment framework for $\mathrm{CH}$ assets in the Philippines exposed to multiple natural hazards. It also investigates innovative, non-invasive techniques and tools for $\mathrm{CH}$-asset survey and diagnostics as well as different retrofitting approaches for Filipino $\mathrm{CH}$ assets, which meet conservation and adaptive reuse criteria.

\section{Review of risk prioritisation schemes for $\mathrm{CH}$ assets}

Several methodologies for determining the vulnerability and risk prioritisation of buildings are available in the scientific literature and in international guidelines. These approaches often rely on the definition of predetermined structural types (or building classes; e.g. Lagomarsino and Giovinazzi, 2006) and corresponding fragility and/or vulnerability relationships for each class; alternatively, RVS forms and empirically calibrated vulnerability and/or risk indices based on the RVS results (e.g. Uva et al., 2016) are used. Although a comprehensive review of the current state of the art in the field is outside the scope of this paper, a brief overview of relevant risk prioritisation procedures defined for $\mathrm{CH}$ assets is presented in this section.

Even though the procedure introduced by the Federal Emergency Management Agency (FEMA, 2015a, b) is not specifically tailored for $\mathrm{CH}$ assets, it represents an important reference for every risk prioritisation framework based on RVS forms, like the one proposed in this study. Starting from a sidewalk screening of the surveyed building, the procedure described in the FEMA P-154 document consists of (1) definition of the structural type by identifying the primary gravity-load-carrying material of construction and the primary seismic-force-resisting system and (2) identification of building attributes that modify the expected seismic performance with respect to an "average" archetype building representative of the given building class. Scores can be associated with the above features, thus determining a seismic vulnerability index without performing any structural analysis. The scoring framework is directly linked to the probability of collapse of archetype buildings (FEMA, 2015a, b) through the Hazard United States (HAZUS) model (Kircher et al., 2006).

Lagomarsino (2006) proposed one of the first multilevel frameworks for the seismic prioritisation of $\mathrm{CH}$ assets based on the estimation of the structural vulnerability. At the lowest refinement level, the approach allows one to compute a vulnerability prioritisation index based on a macroseismic model (i.e. one which makes use of vulnerability curves obtained through post-earthquake damage data collected for different seismic intensities) to be used with macroseismicintensity hazard maps. The computation of the index requires various (expert) judgements on geometrical and structural features of the surveyed building, which are then used to determine an average vulnerability index and vulnerability modifiers. At the highest refinement level, a structural model (e.g. equivalent-frame model) is used to calculate numerical fragility curves for selected damage states (Lagomarsino and Giovinazzi, 2006). In this procedure the $\mathrm{CH}$-asset value is not directly considered.

D'Ayala et al. (2006) proposed a conceptual approach for the multi-hazard vulnerability assessment of historic buildings. The methodology is based on three steps: (1) hazard screening for the identification of the relative damageability of a given historic building, (2) selection of those hazards that can lead to damage scenarios and estimation of the expected losses through a process of building disassembly, and (3) structural analyses of important building components in order to achieve a higher level of accuracy. For each hazard, the prioritisation index is defined as a holistic score obtained by using a weighted summation of scores related to the building features (e.g. structural materials, preservation condition, geometry). Besides being one of the first multi-hazard vulnerability prioritisation schemes, the study presented a comprehensive approach for assessing the tangible and intangible value of $\mathrm{CH}$ assets. In particular, significance and restorability of $\mathrm{CH}$ assets are used as reference criteria. The significance is defined essentially as a function of the authenticity and originality of the $\mathrm{CH}$ asset, i.e. of its historic and aesthetic character. Its evaluation is based on a wide range of criteria including social, cultural and economic attributes, whereas the evaluation of the restorability requires decisionmaking relative to possible interventions and successful outcomes. In addition to cultural and architectural criteria (e.g. acceptability of restoration), the restorability of a damaged building depends on objective factors, such as availability of original building materials, information on the original structural features and substantial financial support. Finally, indices related to different hazards are combined by using normalised losses of common building typologies in the region with reference to a particular peril as weights.

Yu and Oreta (2015) presented a multi-hazard risk prioritisation scheme for $\mathrm{CH}$ buildings which explicitly considered the asset value. The risk prioritisation index is defined as the weighted summation of mitigation and vulnerability factors, whose relative importance is considered through the use of the AHP for the calculation of the weights. The authors proposed an innovative procedure for the quantification of the tangible and intangible value of $\mathrm{CH}$ assets based on both objective and subjective criteria. The asset value is determined by "Cultural Heritage" factors, such as architectural and historical values, and "Economic/Tourism" factors, such 
as commercial use, tourism importance and adaptive reuse adaptability. The total asset value is given by the weighted summations of all these characteristics, where the weights are calibrated through the AHP and based on expert judgements. The scores related to each characteristic are derived through a "focus group discussion" consisting of different stakeholders, such as technicians, historians and inhabitants.

D'Ayala et al. (2016) proposed a procedure for the multihazard vulnerability prioritisation and assessment of $\mathrm{CH}$ assets based on structural models and synthetic scores related to information gathered through a specifically defined RVS form. In particular, the Failure Mechanism Identification and Vulnerability Evaluation (FaMIVE) method (D'Ayala, 2005, 2013) is used to calculate the seismic vulnerability and then a seismic prioritisation index. An engineering-based load and resistance approach, which considers both pullout failure of the first fastener (screw or nail) and pullover failure of the first roof panel, is used to assess the wind vulnerability. Structural components and system resistances (i.e. capacity) are treated as uncertain parameters in the simulations, while gravity and wind load effects (i.e. demand) are considered deterministic (Song et al., 2019). The CH-asset value is considered only in the assessment of flood vulnerability, which is based on RVS forms, and it defines the prioritisation index as the average of scores related to different vulnerability factors (e.g. Stephenson and D'Ayala, 2014).

Despotaki et al. (2018) presented a procedure for the evaluation of the seismic risk of $\mathrm{CH}$ sites in Europe for prioritisation purposes. The approach exploits the methodology proposed by Lagomarsino (2006) for the calculation of baseline vulnerability indices. In order to consider the uniqueness of each asset, vulnerability indices are adjusted based on specific parameters of monuments (e.g. position, state of maintenance or the damage level). The authors applied the proposed procedure to important UNESCO (United Nations Educational, Scientific and Cultural Organization) sites, thus highlighting its feasibility in the vulnerability assessment of large $\mathrm{CH}$ building portfolios.

Moratti et al. (2019) proposed a multilevel approach for the seismic assessment of URM churches based on five levels of data collection which lead to three levels of analysis refinement. At each level, performance indices are calculated as the ratio of the structural capacity and the seismic demand, both expressed in terms of displacement. At the lowest refinement level, statistical data of church characteristics, which do not require building inspections, are used to perform displacement-based assessments in which structures are approximated through single-degree-of-freedom (SDoF) systems. The second refinement level requires building inspections in order to define SDoF models for each pier constituting the surveyed churches. In this way, the same methodology developed for the lowest refinement level can also be applied in this case. The highest refinement level requires detailed data in order to build proper global in-plane structural models and local out-of-plane models. The global seismic behaviour can be evaluated by using SDoF models of each pier or multi-degree-of-freedom (MDoF) models (e.g. equivalent-frame models), which are then used within displacement-based assessment methods in order to apply the same procedure defined for the previous levels. The local outof-plane behaviour is assessed through kinematic analyses, linear or non-linear.

Romão and Paupério (2020) presented an approach for the quantification of economic losses related to $\mathrm{CH}$ assets damaged by catastrophic natural events. Particularly interesting, for the scope of this study, is the definition of the baseline pre-disaster value of the $\mathrm{CH}$ asset which corresponds to the assets' intangible value. The authors consider four categories (i.e. evidential, historical, aesthetic and communal values) reflecting different levels of $\mathrm{CH}$-asset significance (Kerr, 2013). This approach requires only a little information about the assets under investigation and then it can be used at portfolio level for risk prioritisation and assessment.

This brief literature review shows that the few prioritisation approaches which explicitly consider the tangible and intangible value of a $\mathrm{CH}$ asset and/or multiple hazards often require detailed information about the structure under investigation. This can contrast with the nature of risk prioritisation methods at portfolio scale which should require only a small number of data. Moreover, as discussed in Sect. 1, such procedures are widely needed in developing countries where specific data are usually not available, thus requiring several simplifying assumptions. The quantification of losses for $\mathrm{CH}$ assets is further complicated by the subjective definition of the intangible asset value and the difficulties in assigning a value to the non-market nature of assets.

\section{The CHeRiSH framework for the multi-hazard risk prioritisation of cultural heritage assets}

The multi-hazard risk prioritisation approach proposed in this study is part of a broader project (CHeRiSH) which has different objectives involving civil and structural engineering as well as social science and the arts and humanities. From the engineering perspective, the project aims to investigate innovative, non-invasive techniques and tools for $\mathrm{CH}$-asset survey and diagnostics and to develop new methods and models, along with their implementation tools, for the multi-hazard risk and resilience assessment of $\mathrm{CH}$ assets. The main focus of the project is on the exposure and physical vulnerability modelling of $\mathrm{CH}$ assets as well as on the prioritisation of resilience-improving solutions for selected assets through multi-criteria decision-making. From the social science perspective, the main objectives are related to the promotion of community awareness of the vulnerability of $\mathrm{CH}$ assets and the design of disaster risk communication and emergency management campaigns targeted at cultural organisations and local communities. 


\section{Data collection}
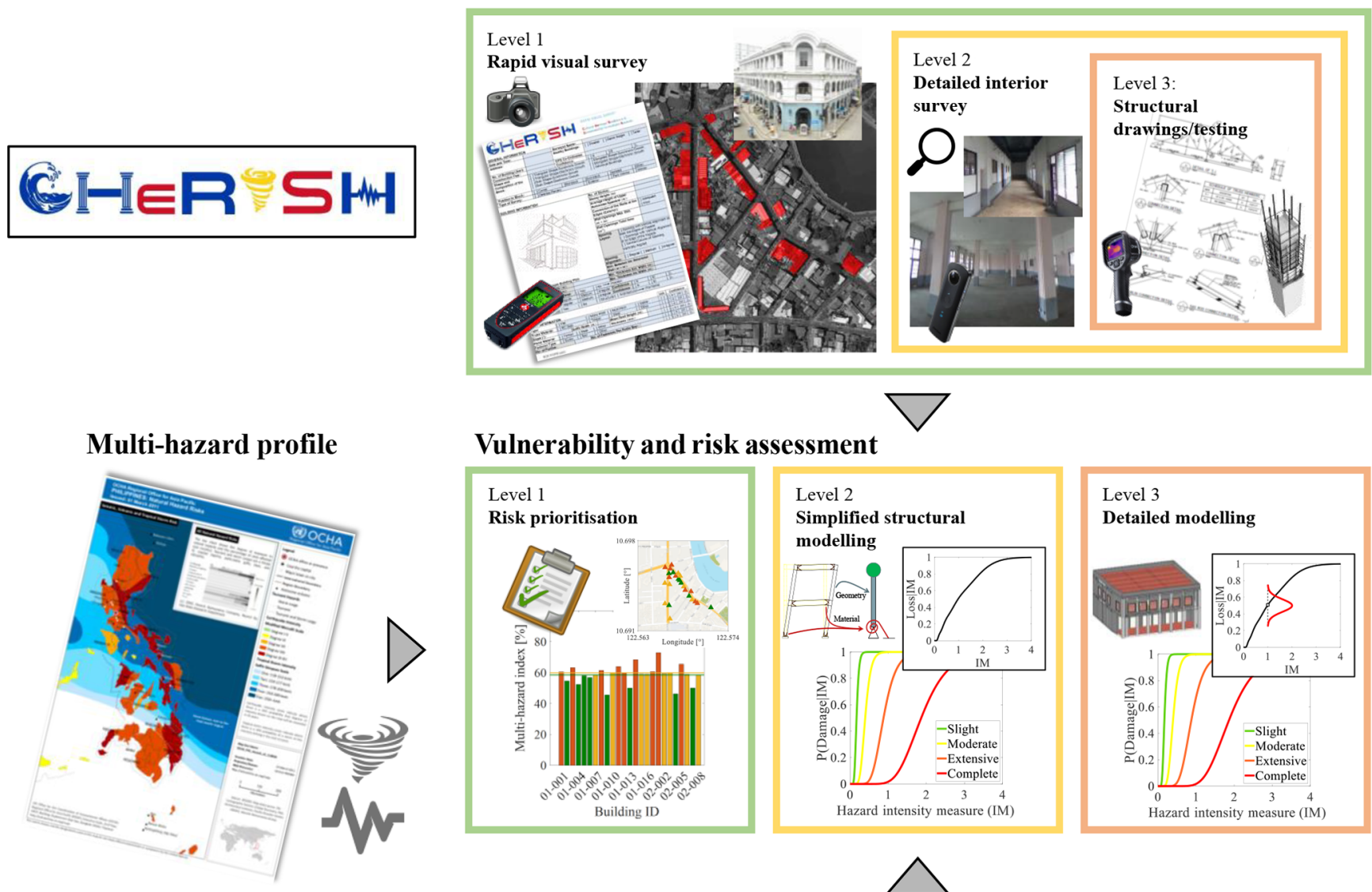

Vulnerability and risk assessment

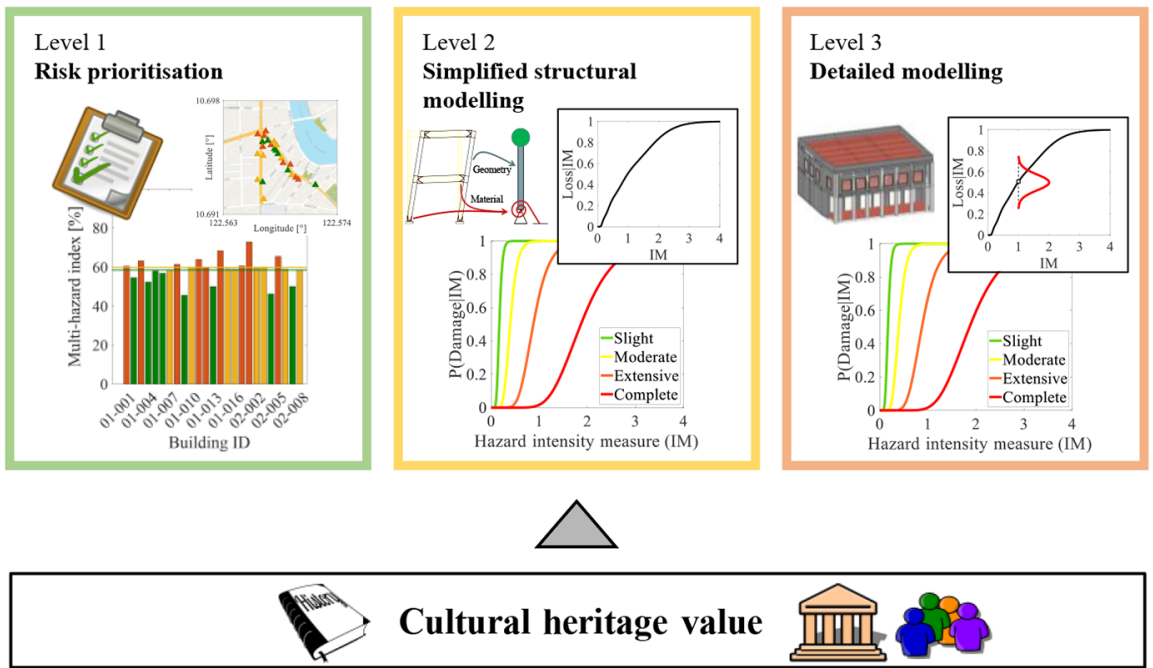

Figure 1. CHeRiSH multilevel, multi-hazard risk assessment framework.

The overall risk and resilience assessment framework proposed in CHeRiSH has a multilevel structure (Fig. 1), consisting of three refinement levels which are directly linked to the amount of available information. The lowest refinement level enables an analyst to perform risk prioritisation of the various $\mathrm{CH}$ assets within a given portfolio, while the others two levels can allow for the estimation of the assets' structural vulnerability and ultimately structural risk at a buildingspecific level, thus increasing the accuracy of the analysis.

Specifically, the multi-hazard risk prioritisation procedure for $\mathrm{CH}$ assets (lowest refinement level) proposed in CHeRiSH can be seen as a five-step procedure, only requiring a little basic information about the structures under investigation. These five steps are as follows: (1) data collection through a sidewalk survey (by means of the proposed RVS form), (2) selection of the hazard-intensity level (e.g. for a selected mean return period) for which the prioritisation is needed, (3) calculation of risk prioritisation indices for different hazards, (4) combination of the different single-hazard prioritisation risk indices, and (5) calculation of multi-hazard risk prioritisation indices which account for the intangible value of $\mathrm{CH}$ assets and building ranking.

At the second refinement level, data from both the asset interior and exterior are used to build simplified structural models which can be used to enhance the assessment of the structural performances. Since no specific information about materials or details is available at this refinement level, the parameters of the structural models are treated as random variables or assumed based on simulated design. At the highest refinement level, structural drawings are required to develop detailed structural models (e.g. finite-element models) for the evaluation of the $\mathrm{CH}$-asset performance for various loading conditions. Material test results as well as non-destructive testing that aims to determine structural details can also be used for the calibration of numerical models, thus reducing the uncertainty in the results. 

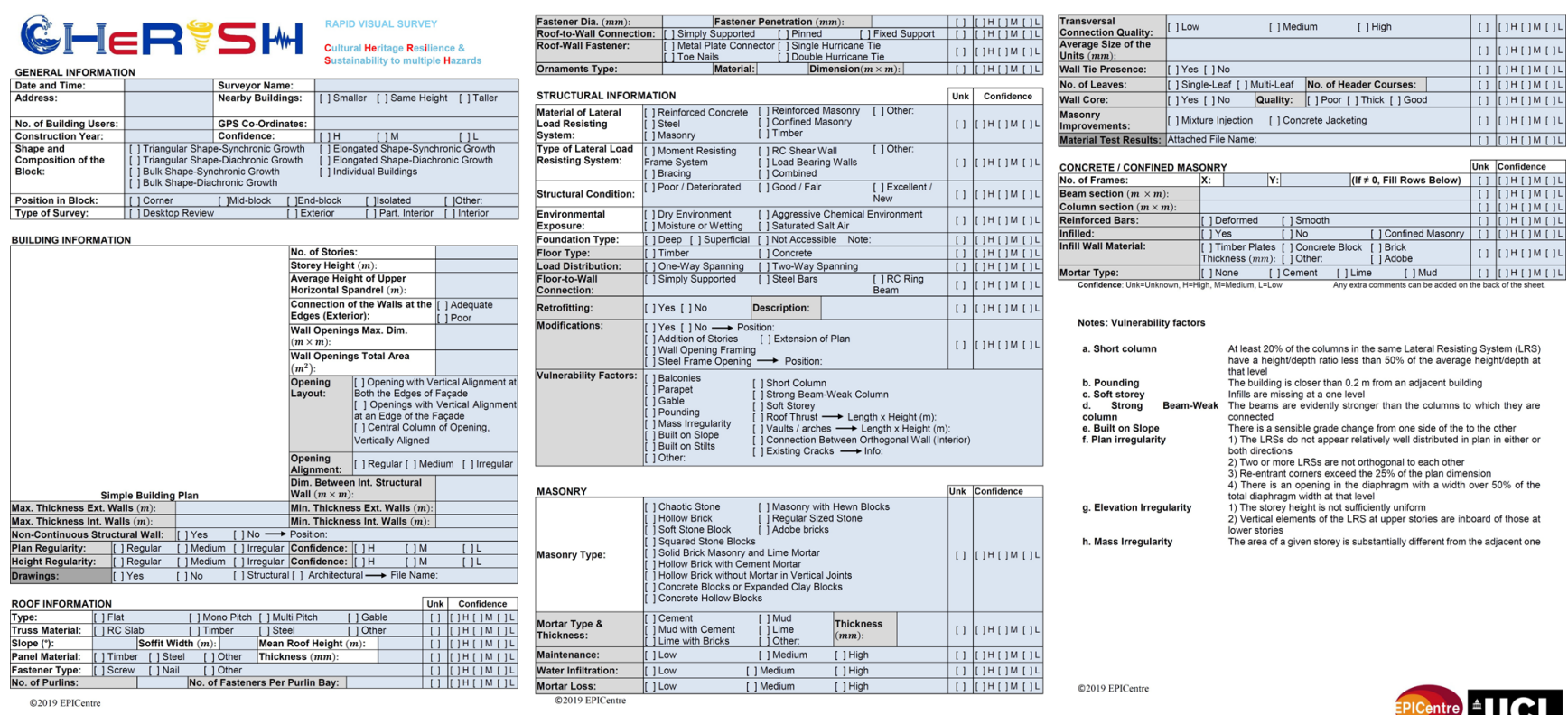

h. Mass Irregularity

Figure 2. CHeRiSH RVS form. The full RVS form in its original $3 \times$ A4-size pages is available online as supplemental material to this paper.

\subsection{The CHeRiSH rapid-visual-survey form}

The proposed RVS form has been designed in order to account for the specific features of Filipino $\mathrm{CH}$ assets, which mainly consist of RC frames and masonry or mixed structures. It is worth noting, however, that even though the RVS form can be used to collect data related to combined structural typologies, such data are not explicitly considered (in terms of scores and weights) in the proposed multi-hazard risk prioritisation framework presented in this study.

According to the Filipino Republic Act No. 10066 (2009), also known as the National Cultural Heritage Act, the only objective feature which defines a building as a $\mathrm{CH}$ asset is the year of construction. Structures which are at least 50 years old can be declared to be a "Heritage House" by the National Historical Commission of the Philippines (NHCP). Differently from the criteria applied by UNESCO (Vecco, 2010) for the definition of $\mathrm{CH}$ assets, the Filipino law does not explicitly consider subjective features of the buildings such as the architectonic value and sociocultural factors. Therefore, fairly recent RC-frame-type structures, characterised by limited architectural and/or cultural features, are often part of the Filipino $\mathrm{CH}$ portfolio. Considering these specific characteristics of the Filipino $\mathrm{CH}$ assets, the proposed RVS form has been designed for various structural typologies employing different construction materials and lateral-load-resisting systems.

As discussed above, the proposed RVS form (Fig. 2) is defined in a multilevel framework. The basic information required for the first level of refinement can be collected by means of a sidewalk survey of the building by trained engineers in approximately $20-30 \mathrm{~min}$, depending on the size of the construction. The second level of refinement or accuracy (light grey entries) requires more detailed data on the structure (e.g. presence of non-continuous structural walls, type and quality of roof-to-wall connections, diaphragm typology) which can be collected only by surveying the building from both its exterior and its interior. The third level of refinement or accuracy (dark grey entries) requires material test results and structural drawings in order to calibrate reliable numerical models.

The RVS form is composed of six sections over three pages; it includes various parts related to the general identification and geolocation of the building; its geometric properties (including space for sketching the building's shape and footprint); and its structural characteristics and deficiencies, including the structural typology and the dimensions and details of the main structural members. It is also possible to assign a confidence level to each parameter, thus accounting for the degree of uncertainty in the collected data. Special emphasis has been placed on the design of the "Vulnerability Factors" and the "Roof Information" sections. The Vulnerability Factors section contains a list of vulnerabilities which can be found in the survey of masonry or RC structures. In addition, $\mathrm{CH}$ assets in the Philippines are particularly vulnerable to typhoon-induced strong wind, as recent catastrophic events have demonstrated. Since the main collapse mechanisms due to extreme wind and typhoons are related to the failure of roofs (Vickery et al., 2006), the Roof Information section requires data about the roof geometry, its structure and connection to the walls, and the quality and the conservation of the materials and fasteners. The data collected in the CHeRiSH RVS form are fully compatible with both the Global Earthquake Model (GEM) building taxonomy (Brzev 
et al., 2013) and the HAZUS model. Hence, existing prioritisation indices based on these two models can also be used within the CHeRiSH framework.

\section{The use of new technologies for $\mathrm{CH}$-asset survey and diagnostics}

$\mathrm{CH}$ assets located in highly populated cities are deeply integrated within the urban fabric, and they may host private and public activities. This can slow down survey campaigns because it limits the possibility of accessing areas of the building and of properly collecting data. Moreover, the time available to carry out the survey is usually limited because of the high costs involved per person per hour. In order to improve the quantity and quality of the data collected on-site without increasing the number of personnel involved, new technologies can be effectively utilised during fieldwork.

Indeed, one of the objectives of the $\mathrm{CHeRiSH}$ project was to test the feasibility of applying new technologies for the survey of $\mathrm{CH}$ assets. In particular, omnidirectional cameras, thermal cameras, drones, photogrammetry and building information modelling (BIM) have been extensively used during the fieldwork discussed in Sect. 4 of this paper.

Omnidirectional cameras (also known as $360^{\circ}$ cameras) are devices that have two wide angle $\left(>85^{\circ}\right)$ fisheye lenses mounted back-to-back and facing in opposite directions, that are each able to photograph $180^{\circ}$ of a scene. The camera can then produce two unstitched $180^{\circ}$ pictures which can also be stitched together to form one $360^{\circ}$ (equirectangular) picture. The $360^{\circ}$ pictures can be used during a desktop review to build 3-D point clouds of the asset interior, to find lost data and to assess the presence, type, and location of non-structural elements. Interior 3-D point clouds can be used to determine distances and heights of the structural members which cannot be directly acquired in the field because of the activities hosted by the surveyed buildings. Non-structural elements can be a source of vulnerability, so their presence must be considered during the definition of resilience-enhancing strategies.

Similarly, the collection of reliable measurements of the building exterior is a challenging task, especially in densely populated cities. Indeed, car traffic, people and temporary obstacles can prevent the architectural survey. Therefore, as in the case of interior measurements, exterior point clouds can be analysed during a desktop review, allowing a more accurate definition of the building dimensions. Exterior point clouds can be built by using photogrammetry technology (e.g. Aicardi et al., 2018) which allows for the transforming of pictures, such as the ones taken by smartphones, into measurable objects.

In addition, the use of a quadcopter drone can further help an analysis to overcome various building access issues that are frequently encountered on-site. Specifically, drones can have the most influential impact in the quality and quantity of data collected for the roof survey. It is worth noting that post-event surveys in the Philippines and around the world reveal that most economic loss in high-wind-hazard areas is related to the breach of the building envelope, particularly roofs. The breach of a building envelope typically includes roof panel uplift, roof-to-wall connection failure, roof system damage, and rupture of window and door glass due to excessive pressure or missile impact. With the roof heavily damaged or removed, walls may become unstable without sufficient lateral support and can collapse. Hence, during strong typhoons, non-engineered roofs built with low-quality materials (typical of $\mathrm{CH}$ assets) and showing heavy material degradation (due to ageing) are highly vulnerable to wind uplift. The collection of data on roof characteristics is usually very difficult because of the roofs' inaccessibility. The data required for the calculation of the wind prioritisation index defined in this study can be assessed much more quickly by using a drone rather than through direct access to or inspection of the roof.

Finally, the quality and typology of the masonry characterising a given asset and the diaphragm characteristics (e.g. its orientation) are essential data needed even at the first refinement level of the proposed framework. Due to the activities hosted within the considered $\mathrm{CH}$ assets and their architectural value, specific (invasive) inspection tests cannot be performed. Non-invasive techniques such as thermal cameras may play an important role in the collection of this information. Thermal cameras allow one to detect infrared energy (heat) and convert it into an electronic signal, which is then processed to produce a thermal image. Since heat sensed by a thermal camera can be very precisely measured and materials are characterised by different thermal properties (e.g. emissivity coefficients), their presence within the structure can be easily detected by just taking a picture. However, the use of thermal cameras is strictly related to the presence of thermal flux within the surveyed structural element. If the system is in thermal equilibrium, the different thermal characteristics of the materials are not highlighted, and then their presence cannot be properly detected.

The use of new technologies, as described above, drastically increases the stream and quantity of information and data which can become prohibitive to manage. Therefore, a suitable BIM platform is currently under development within the CHeRiSH project. The platform is designed to store all the data collected during the fieldwork in Iloilo City, and it will allow an analyst to create accurate 3-D models (architectural and structural ones) of the surveyed buildings. This can be achieved by exploiting the interior and exterior point clouds created by using the photogrammetry and omnidirectional cameras respectively. The BIM platform can also play a crucial role in accessing the vulnerability data of the surveyed $\mathrm{CH}$ assets and in managing resilience-enhancing strategies. 
Table 1. Evolution of seismic codes in the Philippines. NBCP is National Building Code of the Philippines; NSCP is National Structural Code of the Philippines; PHIVOLCS is Philippine Institute of Volcanology and Seismology.

\begin{tabular}{ll}
\hline Philippines design code (edition) & $\begin{array}{l}\text { Basis for general and earthquake loading } \\
\text { provisions }\end{array}$ \\
\hline NBCP 1972 (first edition; second printing in 1977) & UBC 1970 \\
\hline NBCP 1982 (second edition) & UBC 1978 \\
\hline NSCP 1987 (third edition) & UBC 1985 \\
\hline $\begin{array}{l}\text { NSCP } 1992 \text { (fourth edition, Volume 1, Buildings, Towers, and Other } \\
\text { Vertical Structures; Volume 2, Bridges, published in 1997) }\end{array}$ & UBC 1988 \\
\hline $\begin{array}{l}\text { NSCP 2001 (fifth edition, Volume 1, Buildings, Towers, and Other } \\
\text { Vertical Structures) }\end{array}$ & $\begin{array}{l}\text { UBC 1997 - inclusion of active fault maps } \\
\text { from PHIVOLCS }\end{array}$ \\
\hline $\begin{array}{l}\text { NSCP 2010 (sixth edition, Volume 1, Buildings, Towers, and Other } \\
\text { Vertical Structures) }\end{array}$ & $\begin{array}{l}\text { UBC 1997 - inclusion of active fault maps } \\
\text { from PHIVOLCS }\end{array}$ \\
\hline $\begin{array}{l}\text { NSCP 2015 (seventh edition, Volume 1, Buildings, Towers, and } \\
\text { Other Vertical Structures) }\end{array}$ & $\begin{array}{l}\text { UBC 1997 - updated active } \\
\text { fault maps presented by region }\end{array}$ \\
\hline
\end{tabular}

\subsection{The seismic-risk prioritisation index}

In this study, the INSPIRE index (Gentile et al., 2019) for the seismic-risk prioritisation of RC buildings is extended to URM buildings. The need for this extension is justified by the composition of the Filipino $\mathrm{CH}$ portfolio, which counts different structural typologies, including URM buildings. The INSPIRE index, as well as the proposed one for $\mathrm{CH}$ assets $\left(I_{\mathrm{S}}\right)$, is an empirical proxy for the relative seismic risk of various buildings within a given building portfolio. It consists of two components: a baseline score $\left(I_{\mathrm{BL}}\right)$ and a performance modifier $\left(\Delta I_{\mathrm{PM}}\right)$, which are finally summed up to obtain the total seismic-risk index (Eq. 1).

$I_{\mathrm{S}}=I_{\mathrm{BL}}+\Delta I_{\mathrm{PM}}$

The extension of the INSPIRE index to include URM buildings has required the definition of a proper performance modifier, as described in detail in this section. However, guidance on the computation of the RC-building performance modifier is also provided, because of the high occurrence of this structural typology within the analysed $\mathrm{CH}$ portfolio (Sect. 4).

The calculation of the baseline score is based on the fragility curves available in the HAZUS model (Kircher et al., 2006), which represents a harmonised and transparent framework for the multi-hazard fragility, vulnerability and risk assessment of a wide range of structures. The use of the HAZUS model as a starting point for the definition of the proposed seismic-risk prioritisation index is further justified by the fact that several countries around the world, including the Philippines, have adopted seismic provisions which are consistent with the recommendations of the Uniform Building Code 1994 (UBC; ICBO, 1994). In fact, this code is used as a benchmark to define four seismic code levels in the HAZUS framework. The four code levels are high, mod-
Table 2. HAZUS building seismic-design-level classifications.

\begin{tabular}{ll}
\hline $\begin{array}{l}\text { Construction } \\
\text { data }\end{array}$ & $\begin{array}{l}\text { FEMA HAZUS code compliance } \\
\text { assignment }\end{array}$ \\
\hline $\begin{array}{l}\text { Post-2001 } \\
1991-2001\end{array}$ & $\begin{array}{l}\text { Loderate code (for NSCP 2001-2010) } \\
1970-1990\end{array}$ \\
Pre-1970 & No code (for NSCP 1992) \\
\hline
\end{tabular}

erate, low and pre-code (not seismically designed) level. The first three levels are defined with regard to the provisions in the UBC (ICBO, 1994) for seismic zone 4, 2b and 1 respectively. Indeed, the National Structural Code of the Philippines (NSCP, 2015) is the primary design code in the country, providing guidance to civil and structural engineers on the design and assessment of buildings and any other structures since its first edition in 1972. Table 1 shows the history of the NSCP. The post-2001 NSCP versions are all based on the 1997 UBC, and earlier versions were similarly based on previous editions of the UBC, as shown in Table 1, allowing for the proposed mapping with the HAZUS code levels. Based on the data collected during the survey, four separate vintages can be identified: post-2001 (which also includes post-2010, i.e. all the buildings designed to be consistent with the UBC 1997), 1991-2001, 1970-1990, and pre-1970 (Table 2). Results from the on-site surveys often show that the actual construction practice does not closely follow the design plans and code specifications; in those cases, the code compliance for each design vintage can be downgraded by one level for the analysis.

The HAZUS fragility curves express the seismic performance of archetype buildings (for a given structural type) which are classified based on four parameters: 
material (Mat), basic structural system (BSS), building height (Height) and seismic code level (Code Level). Such fragility curves are lognormal cumulative distribution functions (CDFs) expressing the conditional probability that the given structure will reach or exceed a predefined damage state (DS) given the hazard intensity measure (IM). The HAZUS model fragility curves are defined in terms of median $(\mu)$ and dispersion $(\beta$; i.e. the logarithmic standard deviation) parameters in terms of different IMs, including the peak ground acceleration (PGA), and for various DSs, i.e. slight, moderate, extensive and complete damage (see Kircher et al. (2006) for details).

The calculation of the baseline score requires the selection of a target DS, a set of building classes (characterised by a combination of Mat, BSS, Height and Code Level, and one or more hazard levels (in terms of the considered IM). Such hazard levels must be selected based on the seismicity of the considered building portfolio and geographic area and the considered performance objective. The DS exceedance probability for each considered building class can thus be computed for the considered IM level(s). Specifically, considering PGA to be the reference IM, the building basic parameters are mapped onto the exceedance probability of the selected DS ("extensive damage state" or $\mathrm{DS}_{3}$ in this study) conditional on the PGA level, as in Eq. (2).

$$
P_{\mathrm{HAZUS}}=P\left(\mathrm{DS} \geq \mathrm{DS}_{3} \mid \text { Mat, BSS, Code Level, Height, } \mathrm{PGA}\right)
$$

Baseline scores are then calculated in order to be proportional to such exceedance probabilities after a rescaling in the range $[1 \%, 50 \%]$ based on the minimum and maximum DS exceedance probability in the complete (nonfiltered) HAZUS database, as follows:

$$
\begin{aligned}
I_{\mathrm{BL}} & =\left(\frac{50-1}{P_{\mathrm{HAZUS}, \max }-P_{\mathrm{HAZUS}, \min }}\right) \\
& \times\left(P_{\text {HAZUS }}-P_{\text {HAZUS, min }}\right)+1 .
\end{aligned}
$$

In Eq. (3), $P_{\text {HAZUS, max }}$ and $P_{\text {HAZUS, min }}$ are the maximum and minimum DS exceedance probability in the HAZUS database for the selected level(s) of PGA, while $P_{\text {HAZUS }}$ is the DS exceedance probability of the considered building, for the chosen level of PGA. Figure 3 shows the fragility curve set related to the extensive damage state for RC and URM buildings adopted in this study. The extensive damage state is arbitrarily selected for illustrative purposes in this study, and it is mainly related to the life-safety performance objective; other DSs can be key to ensuring the integrity of $\mathrm{CH}$ assets and can be considered in the proposed framework.

The performance modifier $\left(\Delta I_{\mathrm{PM}}\right)$ represents the perturbation of the baseline score due to the presence of vulnerability factors. Its calculation requires the definition of secondary parameters selected with respect to the construction features of the investigated portfolio in order to complement the information in the HAZUS fragility curves. Therefore, the baseline score provides the (conditional) seismic risk of a given

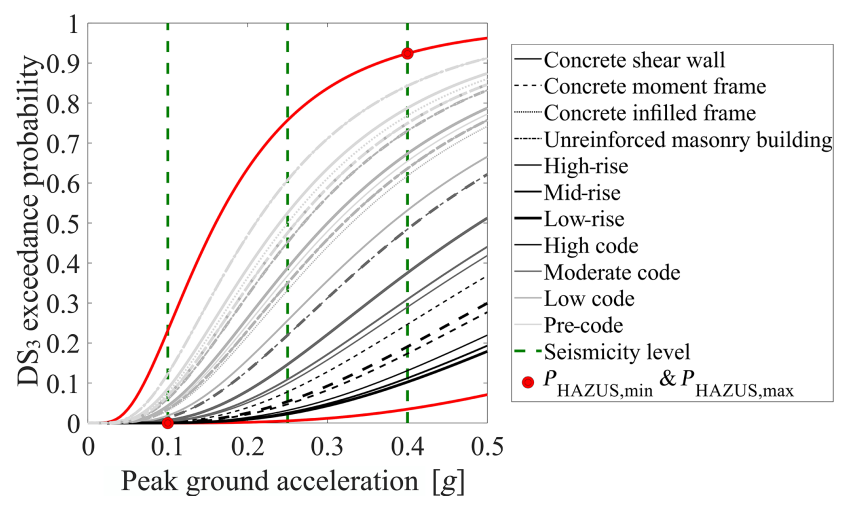

Figure 3. HAZUS fragility curve database related to $\mathrm{DS}_{3}$ (extensive damage state) for RC and URM buildings.

building class, while the secondary parameters are related to building-specific vulnerability factors.

In its original version (Gentile et al., 2019), the performance modifier is defined as the weighted summation of scores $\left(\mathrm{SCORE}_{\text {seismic }}\right)$ which describe different alternatives of each secondary parameter and which are defined according to a uniform partitioning of the range [0\%, $100 \%]$, typically based on engineering judgement. The weights $\left(w_{\mathrm{SP}}\right)$ are needed to reflect the relative importance of the considered secondary parameters, which affect the seismic behaviour of buildings in different ways. In this work, the AHP (Saaty, 1980) is used to calibrate such weights. This process allows an analyst to conduct a rational and mathematically consistent assignment of the weights; starting from expert judgements on every possible pairwise comparison of the secondary parameters, collected into a so-called decision matrix, the AHP allows one to obtain the values of the weights by solving an eigenvalues problem.

In particular, the seismic vulnerability assessment of URM buildings requires consideration of the quality of the material (e.g. Borri et al., 2015), the out-of-plane mechanisms (e.g. Sorrentino et al., 2017; D'Ayala and Speranza, 2003) and the in-plane behaviour (e.g. Lagomarsino et al., 2013; Novelli et al., 2015). These factors, together with the presence of façade ornaments, have been considered as macrocategories for the definition of the URM building performance modifier (Fig. 4). According to the scientific literature (e.g. Borri et al., 2015), the material quality, which expresses the quality of the masonry, strongly affects the seismic response of the structure. The material quality is thus calculated based on the masonry typology (e.g. uncoursed rubble stones, hollow brick and regular-sized stone, solid brick masonry with lime mortar, concrete blocks) and the masonry degradation. If the material quality is not sufficiently high, the structure cannot develop the so-called out-of-plane mechanisms. Therefore, this parameter must be considered more important than the others. The out-of-plane behaviour is the second most important macro-category. Indeed, if out-of- 
plane mechanisms are not avoided, the structure cannot behave as a unique fabric (e.g. Sorrentino et al., 2017). When the material quality is sufficient and the out-of-plane mechanisms are prevented, then the in-plane behaviour must be assessed (e.g. Lagomarsino et al., 2013; Croce et al., 2019), and of course it is more important than the presence of nonstructural façade ornaments (Fig. 3). The expert judgements (Table A1) used in this study for the calibration of the macrocategory weights $\left(w_{\mathrm{MC}, m}\right)$ through the AHP reflect these considerations. Clearly, the decision matrix adopted in this study reflects the characteristics of the Filipino $\mathrm{CH}$ assets and the expert opinion of the authors (academic and professional engineers across the UK and the Philippines); it should be further calibrated before the entire procedure can be applied for the analysis of different building portfolios.

The secondary parameters collected within each macrocategory have been selected based on the fundamental rules of masonry structure design (e.g. Heyman, 1997; Paulay and Priestley, 1992) and the commonly observed post-earthquake damage on URM structures (e.g. Fiorentino et al., 2018; Mazzoni et al., 2018). For this reason, parameters related to the geometry and the regularity of the façade (opening layout, wall slenderness, opening alignment and opening area) as well as those related to connections (wall-to-wall connection, floor-to-wall connection and wall-to-roof connection) are considered for the definition of the out-of-plane behaviour. Indeed, it is well known that the activation of outof-plane mechanisms is strictly linked to the geometry of the piers (i.e. opening layout), which is also determined by the position of the openings (i.e. opening alignment), and the connection with orthogonal walls, diaphragms and roof (D'Ayala, 2005). In this study, the presence/quality of connections has been valued more important than the geometry and regularity of the façades, as shown in Table A2. This is because the Filipino $\mathrm{CH}$ portfolio is characterised by buildings with regular opening layouts but various diaphragm typologies, so a proper prioritisation scheme can be achieved by using the proposed judgements. The dimension of the piers, which is linked to the opening layout and the opening alignment, affect both the out-of-plane and the in-plane behaviours (e.g. Parisi and Augenti, 2013) of the URM building resisting members. However, in the proposed approach, these secondary parameters are considered only in the in-plane behaviour component to avoid counting their effect twice.

The regularity of the building (plane shape and storey height uniformity) and the presence of vulnerability factors (added storeys, pounding and unfavourable soil) are used to quantify the in-plane behaviour of URM buildings. The regularity of the Filipino $\mathrm{CH}$ assets leads us to assign greater importance to vulnerability factors, such as pounding and unfavourable soil, than to the others, thus achieving a relatively more accurate prioritisation scheme (Table A3).

Table 3 provides guidance on the selection of the alternatives for the calculation of the URM building performance modifier.
The performance modifier can be finally calculated as in Eq. (4),

$\Delta I_{\mathrm{PM}}=\frac{1}{2} \sum_{m=1}^{M} w_{\mathrm{MC}, m} \sum_{n=1}^{N_{m}} w_{\mathrm{SP}, n} \mathrm{SCORE}_{\mathrm{seismic} ; m, n}$,

where $M$ is the total number of macro-categories, $N_{m}$ is the number of secondary parameters within the $m$ th macrocategory and the subscript $n$ indicates the considered secondary parameter.

The secondary parameters for the calculation of the RCstructure performance modifier are selected according to Gentile et al. (2019). Having no macro-categories in this case, the weights $w_{\mathrm{MC}, m}$ in Eq. (4) are assumed equal to 1, while the secondary parameters weights $w_{\mathrm{SP}, n}$ are calibrated through the AHP to reflect the expert judgements indicated in Table A4; see Gentile et al. (2019) for a critical discussion on the assumptions made here. These parameters express the preservation condition of the material, the regularity of the structure (plane shape, storey height uniformity and added storeys), the presence of vulnerability factors (infills at ground storey, short column and pounding) and the soil conditions (unfavourable soil); these parameters can capture various vulnerability factors observed in post-earthquake damage surveys of RC buildings (e.g. De Luca et al., 2018).

The expert judgements expressing the relative importance of the considered RC-building secondary parameters (Table A4) are calibrated accounting for the peculiarities of Filipino $\mathrm{CH}$ assets. In particular, infills at ground storey, presence of short columns and potential for pounding have been valued as more important than the other secondary parameters. Indeed, many Filipino $\mathrm{CH}$ assets have non-engineered structures resulting from reconstructions and/or modifications over time. Therefore, these three vulnerability factors are commonly diffused. This choice results in a higher variability in the prioritisation scheme. Table 4 provides guidance on the selection of the alternatives for the assignation of scores to the secondary parameters.

One of the most important advantages of the proposed approach is the possibility of easily adapting it for the prioritisation of other building typologies by simply considering various secondary parameters and modifying the expert judgements and weights to reflect different construction features and their relative importance on the asset vulnerability. Only the consistency of the opinions must be checked through the calculation of a consistency index (CI) as in Eq. (5), after the pairwise comparison:

$\mathrm{CI}=\frac{\lambda_{\max }-r}{r-1}$.

In Eq. (5), $\lambda_{\max }$ is the largest eigenvalue, calculated as the solution of the AHP, while $r$ is the rank of the judgement matrix. Finally, the CI is compared to a random consistency index (RCI), which is the average consistency index of a large number of randomly generated reciprocal matrices. If 
Table 3. Macro-categories and secondary parameters for URM buildings: definition, alternatives, scores and weights.

\begin{tabular}{|c|c|c|c|c|c|}
\hline Macro-category & $w_{\mathrm{MC}}$ & Secondary parameters & $w_{\text {SP }}$ & Alternatives & Scores \\
\hline \multirow[t]{6}{*}{ Material quality } & \multirow[t]{6}{*}{0.4607} & \multirow[t]{3}{*}{ Material typology } & \multirow[t]{3}{*}{0.5} & Uncoursed rubble stones & 100 \\
\hline & & & & Hollow brick and regular-sized stone & 50 \\
\hline & & & & $\begin{array}{l}\text { Solid brick masonry with lime mortar } \\
\text { and concrete blocks }\end{array}$ & 0 \\
\hline & & \multirow[t]{3}{*}{ Material degradation } & \multirow[t]{3}{*}{0.5} & $\begin{array}{l}\text { Significantly affecting performance (poor } \\
\text { structural condition) }\end{array}$ & 100 \\
\hline & & & & $\begin{array}{l}\text { Moderately affecting performance (good } \\
\text { structural condition) }\end{array}$ & 50 \\
\hline & & & & $\begin{array}{l}\text { Not affecting performance (excellent } \\
\text { structural condition) }\end{array}$ & 0 \\
\hline \multirow[t]{18}{*}{ Out-of-plane behaviour } & \multirow[t]{18}{*}{0.2894} & \multirow[t]{3}{*}{ Opening layout } & \multirow[t]{3}{*}{0.0582} & $\begin{array}{l}\text { Opening with vert. alignment at both } \\
\text { edges of the façade }\end{array}$ & 100 \\
\hline & & & & $\begin{array}{l}\text { Opening with vert. alignment at only one } \\
\text { edge of the façade }\end{array}$ & 50 \\
\hline & & & & $\begin{array}{l}\text { Opening with vert. alignment at the centre } \\
\text { of the façade }\end{array}$ & 0 \\
\hline & & \multirow[t]{3}{*}{ Wall slenderness } & \multirow[t]{3}{*}{0.0346} & $\operatorname{High}(h / l \geq 10)^{*}$ & 100 \\
\hline & & & & $\operatorname{Medium}(5 \leq h / l \leq 10)$ & 50 \\
\hline & & & & Low $(h / l \leq 5)$ & 0 \\
\hline & & \multirow[t]{3}{*}{ Opening alignment } & \multirow[t]{3}{*}{0.0975} & Irregular (openings are not aligned) & 100 \\
\hline & & & & Medium (openings are vertically aligned) & 50 \\
\hline & & & & $\begin{array}{l}\text { Regular (openings are horizontally and } \\
\text { vertically aligned) }\end{array}$ & 0 \\
\hline & & \multirow[t]{3}{*}{ Opening area } & \multirow[t]{3}{*}{0.0468} & $\begin{array}{l}\text { High (more than } 50 \% \text { of the total façade } \\
\text { area) }\end{array}$ & 100 \\
\hline & & & & $\begin{array}{l}\text { Medium (between } 25 \% \text { and } 50 \% \text { of the } \\
\text { total façade area) }\end{array}$ & 50 \\
\hline & & & & Low (less than $25 \%$ of the total façade area) & 0 \\
\hline & & \multirow[t]{2}{*}{ Wall-to-wall connection } & \multirow[t]{2}{*}{0.1923} & Poor & 100 \\
\hline & & & & Adequate (mechanical connection) & 0 \\
\hline & & \multirow[t]{2}{*}{ Floor-to-wall connection } & \multirow[t]{2}{*}{0.3696} & Poor & 100 \\
\hline & & & & Adequate (ring beam) & 0 \\
\hline & & \multirow[t]{2}{*}{ Wall-to-roof connection } & \multirow[t]{2}{*}{0.2010} & Poor & 100 \\
\hline & & & & Adequate (mechanical connection) & 0 \\
\hline \multirow[t]{13}{*}{ In-plane behaviour } & \multirow[t]{13}{*}{0.1901} & \multirow[t]{3}{*}{ Plan shape } & \multirow[t]{3}{*}{0.1732} & L-shape or irregular & 100 \\
\hline & & & & C-shape & 50 \\
\hline & & & & Rectangular or regular & 0 \\
\hline & & Storey height uniformity & 0.1125 & $\begin{array}{l}\text { Significantly non-uniform (more than } \\
0.5 \mathrm{~m} \text { difference) }\end{array}$ & 100 \\
\hline & & & & $\begin{array}{l}\text { Moderately non-uniform (difference } \\
\text { between } 0 \text { and } 0.5 \mathrm{~m} \text { ) }\end{array}$ & 50 \\
\hline & & & & Uniform & 0 \\
\hline & & Added storeys & 0.1021 & Yes & 100 \\
\hline & & & & No & 0 \\
\hline & & Pounding & 0.4307 & Pronounced (less than $0.1 \mathrm{~m}$ gap) & 100 \\
\hline & & & & Moderate (gap between 0.1 and $0.2 \mathrm{~m}$ ) & 50 \\
\hline & & & & None (more than $0.2 \mathrm{~m}$ gap) & 0 \\
\hline & & Unfavourable soil & 0.1815 & $\begin{array}{l}\text { Yes (very soft soil; liquefaction is not } \\
\text { explicitly considered) }\end{array}$ & 100 \\
\hline & & & & No & 0 \\
\hline Façade ornaments & 0.0598 & & & Yes & 100 \\
\hline & & & & No & 0 \\
\hline
\end{tabular}

* $h$ and $l$ are the wall height and thickness respectively. 


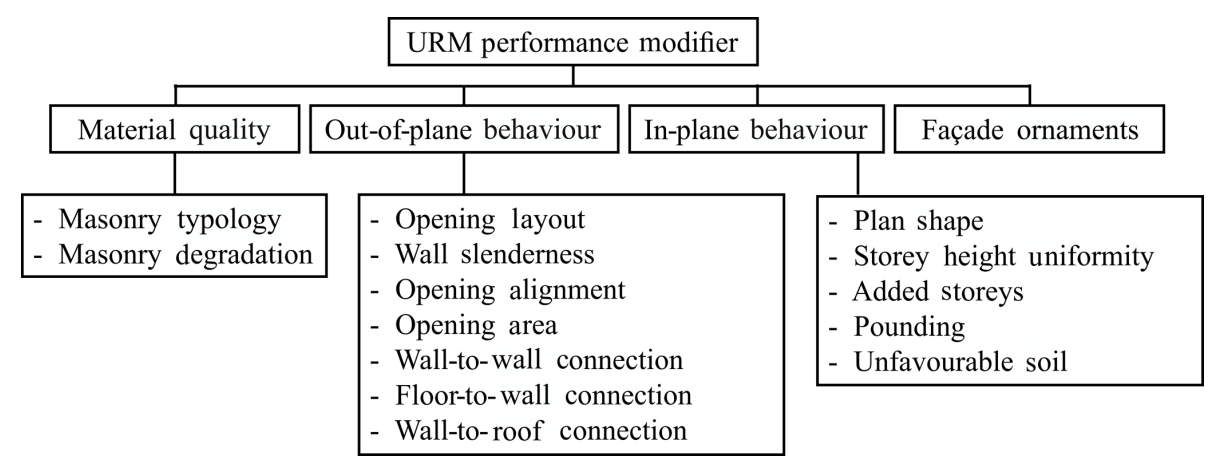

Figure 4. Performance modifier scheme.

Table 4. Secondary parameters of RC buildings: definition, alternatives, scores and weights.

\begin{tabular}{|c|c|c|c|}
\hline Secondary parameters & $w_{\mathrm{SP}}$ & Alternatives & Scores \\
\hline \multirow[t]{3}{*}{ Preservation condition and/or existing damage } & 0.0939 & $\begin{array}{l}\text { Significantly affecting performance (poor structural } \\
\text { condition) }\end{array}$ & 100 \\
\hline & & $\begin{array}{l}\text { Moderately affecting performance (good structural } \\
\text { condition) }\end{array}$ & 50 \\
\hline & & Not affecting performance (excellent structural condition) & 0 \\
\hline \multirow[t]{3}{*}{ Plan shape } & 0.0826 & L-shape or irregular & 100 \\
\hline & & C-shape & 50 \\
\hline & & Rectangular or regular & 0 \\
\hline \multirow[t]{3}{*}{ Storey height uniformity } & 0.0470 & Significantly non-uniform (more than $0.5 \mathrm{~m}$ difference) & 100 \\
\hline & & Moderately non-uniform (difference between 0 and $0.5 \mathrm{~m}$ ) & 50 \\
\hline & & Uniform & 0 \\
\hline \multirow[t]{2}{*}{ Added storeys } & 0.0470 & Yes & 100 \\
\hline & & No & 0 \\
\hline \multirow[t]{2}{*}{ Infills at ground storey } & 0.3039 & Yes & 100 \\
\hline & & No & 0 \\
\hline \multirow[t]{2}{*}{ Short column } & 0.1817 & Yes & 100 \\
\hline & & No & 0 \\
\hline \multirow[t]{3}{*}{ Pounding } & 0.1817 & Pronounced (less than $0.1 \mathrm{~m}$ gap) & 100 \\
\hline & & Moderate (gap between 0.1 and $0.2 \mathrm{~m}$ ) & 50 \\
\hline & & None (more than $0.2 \mathrm{~m}$ gap) & 0 \\
\hline \multirow[t]{2}{*}{ Unfavourable soil } & 0.0621 & $\begin{array}{l}\text { Yes (very soft soil; liquefaction is not explicitly } \\
\text { considered) }\end{array}$ & 100 \\
\hline & & No & 0 \\
\hline
\end{tabular}

the CI is smaller than $10 \%$ of the RCI, the final values of the weights are logically sound and not a result of random prioritisation. When such a criterion is not satisfied, the whole process should be repeated until an acceptable consistency is achieved (Saaty, 1980). The consistency condition is satisfied for all the comparisons used in the definition of the seismic index (macro-categories: $\mathrm{CI}=0.0477 \leq 0.09=10 \% \mathrm{RCI}$; out-of-plane behaviour: $\mathrm{CI}=0.0246 \leq 0.132=10 \% \mathrm{RCI}$; in-plane behaviour: $\mathrm{CI}=0.0615 \leq 0.112=10 \% \mathrm{RCI})$.

\subsection{The wind prioritisation index}

The proposed wind prioritisation index for $\mathrm{CH}$ assets $\left(I_{\mathrm{W}}\right)$ is based on the vulnerability factors proposed by D'Ayala et al. (2020) for the definition of the SCOSSO index, a multihazard vulnerability prioritisation index for Filipino schools. The authors proposed a scoring method based on ratings related to specific building features which are combined to determine an overall damageability index. Particularly important for the aims of this study is the set of roof vulnerability factors related to the wind hazard. The authors considered 
eight construction features, also used in this study, which represent the following: the entire building construction features (code level and number of storeys), the roof construction features (roof structure, roof covering and roof pitch) the roof connection and the material conditions (roof condition and structural condition). As for the case of the seismic prioritisation index, the code level follows the classification proposed by the HAZUS model (Kircher et al., 2006). Adopting the same code classification for the seismic and wind indices enables the proposed procedure to be consistent.

The proposed wind prioritisation index $\left(I_{\mathrm{W}}\right)$ is defined as a proxy for the relative wind risk of the considered buildings within the analysed portfolio. In fact, $I_{\mathrm{W}}$ (Eq. 6) is calculated as the weighted summation of scores $\left(\mathrm{SCORE}_{\text {wind }}\right)$ related to the structure of the roof and the presence of vulnerability factors (Table 5), which is then multiplied by a hazard parameter $\left(\hat{w}_{\mathrm{H}}\right)$.

$I_{\mathrm{W}}=\hat{w}_{\mathrm{H}} \sum_{i=1}^{8} w_{\mathrm{VF}, i} \mathrm{SCORE}_{\mathrm{wind}, i}$

The score values are in the range $[0 \%, 100 \%]$ and they allow analysts to convert a qualitative judgement on the status of a particular vulnerability factor into a quantitative indicator. The hazard parameter reflects the wind hazard of the region where the analysed asset is located. Even though the wind hazard in the Philippines is fairly homogeneous, three regions are herein considered: west coastal areas (low wind hazard), central part of the country (medium wind hazard) and east coastal regions (high wind hazard). In fact, according to the National Structural Code of the Philippines (2015), the wind hazard increases from the east coast to the west coast of the country.

The combination weights $\left(w_{\mathrm{VF}, i}\right)$ are calibrated through the use of the AHP to reflect their relative importance, according to the expert judgements reported in Table A5. As discussed in the previous sections, the non-engineered nature of the Filipino $\mathrm{CH}$-asset roofs promotes pullout (of fasteners) and pullover (of panels) failures. Therefore, the roof connection is considered the most important parameter. Immediately after that, material conditions (for both the roof and the structure) and code level play a fundamental role. Degraded materials can lead to roof failure even if good-quality connections are installed, while modern constructions should ensure a higher level of reliability than older ones (given good connections and materials). The remaining parameters can affect the roof system behaviour only if those previously listed do not significantly affect the roof performance. The judgements assumed for the wind vulnerability factors in this application lead to $\mathrm{CI}=0.0297$ and $\mathrm{RCI}=1.41$, thus satisfying the consistency condition.

The AHP is also used to calibrate the values of the hazard parameters $\left(\hat{w}_{\mathrm{H}}\right)$, reflecting the judgement matrix reported in Table A6. Clearly, areas with high wind hazard are valued as more important than areas with medium and low wind
Table 5. Wind vulnerability factors: definition, alternatives, scores and weights.

\begin{tabular}{|c|c|c|c|}
\hline Vulnerability factors & $w_{\mathrm{VF}}$ & Alternatives & Scores \\
\hline \multirow[t]{4}{*}{ Code level } & 0.1623 & Pre-code & 100 \\
\hline & & Low code & 66 \\
\hline & & Moderate code & 33 \\
\hline & & High code & 0 \\
\hline \multirow[t]{3}{*}{ Number of storeys } & 0.0436 & More than three storeys & 100 \\
\hline & & Two or three storeys & 50 \\
\hline & & One storey & 0 \\
\hline \multirow[t]{3}{*}{ Structural condition } & 0.1725 & Deteriorated-poor & 100 \\
\hline & & Fair-good & 50 \\
\hline & & New-excellent & 0 \\
\hline \multirow[t]{4}{*}{ Roof structure } & 0.0838 & Bricks & 100 \\
\hline & & Timber truss & 66 \\
\hline & & RC slab & 33 \\
\hline & & Steel truss & 0 \\
\hline \multirow[t]{2}{*}{ Roof covering } & 0.0671 & Tiles & 100 \\
\hline & & Iron sheets & 50 \\
\hline \multirow[t]{3}{*}{ Roof pitch } & 0.0943 & Multi-pitch & 100 \\
\hline & & Mono-pitch & 50 \\
\hline & & Flat & 0 \\
\hline \multirow[t]{3}{*}{ Roof condition } & 0.1715 & Deteriorated-poor & 100 \\
\hline & & Fair-good & 50 \\
\hline & & New-excellent & 0 \\
\hline \multirow[t]{3}{*}{ Roof connection } & 0.2049 & Deteriorated-poor & 100 \\
\hline & & Fair-good & 50 \\
\hline & & New-excellent & 0 \\
\hline
\end{tabular}

hazard. The hazard parameters $\left(\hat{w}_{\mathrm{H}}\right)$ are finally determined by normalising the AHP weights $\left(w_{\mathrm{H}}\right)$ as shown in Table 6 . The consistency index and the random consistency index are $\mathrm{CI}=0.046$ and $\mathrm{RCI}=0.58$ respectively.

\subsection{Combination of risk prioritisation indices}

Once prioritisation indices related to different hazards are calculated, they must be properly combined in order to obtain a comprehensive indicator of the relative multi-hazard risk of the considered assets within the analysed portfolio.

In this study the multi-hazard risk prioritisation index $\left(I_{\text {multi }}\right)$ is calculated as the Euclidian norm of the vectors whose components are the $k$ single-hazard prioritisation indices $\left(I_{k} ;\right.$ Eq. 7).

$$
I_{\text {multi }}=\sqrt{\sum_{k} I_{k}^{2}}
$$

Equation (7) can be applied only if the single-hazard risk prioritisation indices $\left(I_{k}\right)$ have the same range of variation. However, the resulting multi-hazard risk prioritisation index $\left(I_{\text {multi }}\right)$ will be characterised by a different range. This 
Table 6. Wind hazard parameters.

\begin{tabular}{lcrl}
\hline Wind hazard & $w_{\mathrm{H}}$ & $\hat{w}_{\mathrm{H}}$ & Description \\
\hline High hazard & 0.540 & 1 & $\begin{array}{l}\text { East coastal areas (basic wind speed with a 15\% probability of exceedance in } \\
50 \text { years - between } 290 \text { and } 320 \mathrm{kph}) .\end{array}$ \\
\hline Medium hazard & 0.297 & 0.550 & $\begin{array}{l}\text { Central part of the country (basic wind speed with a 15\% probability of } \\
\text { exceedance in 50 years - between 270 and 290 kph). }\end{array}$ \\
\hline Low hazard & 0.163 & 0.302 & $\begin{array}{l}\text { West coastal areas (basic wind speed with a 15\% probability of exceedance in } \\
50 \text { years - between 240 and 270 kph). }\end{array}$ \\
\hline
\end{tabular}

can be rescaled to any other desired range without affecting the prioritisation list of the considered building portfolio. This simple combination rule does not introduce any further subjectivity into the framework, and it can be applied even when numerous hazards are considered. However, this method does not consider either the interaction of different hazards at the various levels of the risk assessment chain or weights for the different hazard prioritisation indices.

Loss curves (i.e. loss values versus their annual probability of exceedance) for various individual hazards, calculated for a specific region, show different non-linear trends (Fleming et al., 2016). Therefore, considering different return periods, the relative effect of two catastrophic events (related to two different hazards) on the built environment may completely change. For instance, for low return periods, such as 100 years, earthquake and extreme-wind economic losses are comparable, while for high return periods, such as 1000 years, the economic loss related to seismic events is usually higher than that related to extreme winds. This fact may be considered within the proposed framework by defining suitable combination weights for the single-hazard prioritisation indices in Eq. (7). Such combination weights should vary with the mean return period of interest selected for the prioritisation in order to express how every considered hazard contributes to the total loss. This would require a priori loss curves, which are usually not available for developing countries.

\subsection{The value of $\mathrm{CH}$ assets}

The proper definition of the asset exposure is a fundamental step of the risk assessment process, requiring the quantification of the asset value. As discussed in Sects. 1 and 2, this task is particularly complex for $\mathrm{CH}$ assets because of their multiple impacts (e.g. economic, social, spiritual) which cannot be solely determined in monetary terms, unlike other building typologies. Moreover, the relatively broad definition of cultural heritage adopted in different countries (no standardised definition exists; e.g. European Commission, 2018; Filipino Republic Act No. 10066, 2009) makes the quantification of the $\mathrm{CH}$-asset exposure even more complex. Most of the methods proposed in the scientific literature often neglect the $\mathrm{CH}$-asset exposure, thus considering vulnerability priori- tisation indices or assuming a homogeneous exposure for the whole building portfolio.

The simplified approach for considering the intangible value of $\mathrm{CH}$ assets in the prioritisation scheme (lowest refinement level) proposed in this study assumes that the tangible values (direct and indirect costs) are constant for the entire portfolio so that they do not affect the prioritisation scheme. As discussed in Sect. 1, the intangible value is peculiar to each specific $\mathrm{CH}$ asset, and then it cannot be considered constant for the entire portfolio. Therefore, a score approach is proposed for its quantification through the calculation of the $\mathrm{CH}$ value index $\left(I_{\mathrm{CH}}\right.$ value $)$. It assumes the intangible value linked to the significance as a "monument" of the $\mathrm{CH}$ asset by adopting the classification issued by Kerr (2013). Four categories are considered for the definition of the scores: world heritage, national heritage, national/local heritage and local heritage. Table A7 shows the expert judgements assigned to express the relative importance of each significance category and needed for the calculation of the scores through the AHP. The judgements express the idea that the intangible value increases with the significance of the analysed $\mathrm{CH}$ asset. Table 7 provides guidance for the selection of the appropriate $\mathrm{CH}$ significance, and it reports the relative scores for which the consistency condition is satisfied $(\mathrm{CI}=0.01 \leq \mathrm{RCI}=0.9)$.

It is worth noting that the classification of the $\mathrm{CH}$-asset significance proposed by Kerr (2013) has been already successfully used and validated in the scientific literature for the quantification of the intangible value (e.g. Romão and Paupério, 2020; Figueiredo et al., 2019). This further strengthens the validity of the proposed procedure.

Finally, after a normalisation process of the $\mathrm{CH}$ value in$\operatorname{dex}\left(I_{\mathrm{CH}}\right.$ value $)$, which allows for the calculation of $\hat{I}_{\mathrm{CH}}$ value, the multi-hazard risk prioritisation index which considers the $\mathrm{CH}$ value $\left(I_{\text {multi,CH value }}\right)$ can be calculated as

$I_{\text {multi, } \mathrm{CH} \text { value }}=I_{\text {multi }} \hat{I}_{\mathrm{CH}}$ value . 
Table 7. CH significance scores.

\begin{tabular}{lcrl}
\hline CH status & $I_{\mathrm{CH} \text { value }}$ & $\hat{I}_{\mathrm{CH} \text { value }}$ & Description \\
\hline Exceptional significance & 0.4673 & 1 & $\begin{array}{l}\text { The } \mathrm{CH} \text { asset is considered of world heritage; it is characterised by an } \\
\text { exceptional significance recognised worldwide. }\end{array}$ \\
\hline Considerable significance & 0.2772 & 0.5932 & $\begin{array}{l}\text { The } \mathrm{CH} \text { asset is listed among the } \mathrm{CH} \text { assets of national interest; it has national } \\
\text { significance, and it is possibly protected by national organisations. }\end{array}$ \\
\hline Some significance & 0.1601 & 0.3426 & $\begin{array}{l}\text { The } \mathrm{CH} \text { asset has features of national significance but is insufficient to be recognised } \\
\text { as } \mathrm{CH} \text { of national interest. }\end{array}$ \\
\hline Little significance & 0.0954 & 0.2042 & $\begin{array}{l}\text { The } \mathrm{CH} \text { asset is characterised by local significance, so it has no national } \\
\text { significance. }\end{array}$ \\
\hline
\end{tabular}

\section{Case study - CH assets in Iloilo City, Philippines}

\subsection{Description of Filipino $\mathrm{CH}$ assets}

Recent catastrophic events, e.g. the M 7.2 2013 Bohol earthquake or the 2013 Typhoon Haiyan, have highlighted how Filipino $\mathrm{CH}$ assets are particularly vulnerable to natural hazards due to ageing and type of construction. As already discussed, $\mathrm{CH}$ assets and communities are doubly tied because of their economic and social connections. This link is even more important in developing countries where cultural tourism is seen as one of the priority sectors by which governments aim to foster inclusive and sustainable socioeconomic development, due to its potential for job creation and revenues. For instance, according to the Philippines Statistics Authority (2019), the contribution of tourism to the Philippine economy was $12.7 \%$ of GDP in 2018.

The proposed multi-hazard framework for risk prioritisation of $\mathrm{CH}$ assets has been tested on $25 \mathrm{CH}$ buildings located in Iloilo City, Philippines (Fig. 5), one of the oldest cities and a touristic hub in the country, containing a collection of historic sites, monuments and $\mathrm{CH}$ buildings. Realising the importance of preserving its heritage, the city government has actively pursued promoting the city's culture, by identifying heritage zones and instituting a heritage conservation council to oversee and promote $\mathrm{CH}$ preservation.

With three active faults in the proximity of the city, Iloilo City is listed under Seismic Zone 4 on the official seismic map of the Philippines by the Philippine Institute of Volcanology and Seismology (Association of structural engineers of the Philippines, 2015). According to the GEM (Pagani et al., 2018), the seismic hazard in Iloilo City, in terms of PGA with a $10 \%$ of probability of exceedance in 50 years, is in the range of 0.35 to $0.55 \mathrm{~g}$. Since the city is also situated in Zone II of the Philippines Wind Zone Map (i.e. the $3 \mathrm{~s}$ gust speed at $10 \mathrm{~m}$ above the ground is equal to $117 \mathrm{~km} \mathrm{~h}^{-1}$ by assuming a return period of 50 years), it represents a perfect case study to assess the feasibility of the proposed approach.

The analysed building portfolio is composed of URM and RC-frame-type structures. Most of the building construction

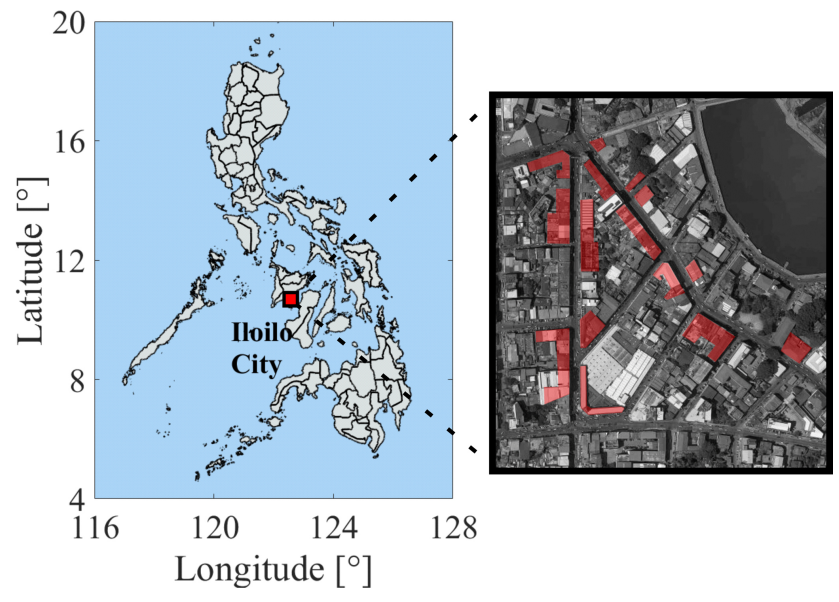

Figure 5. Surveyed $\mathrm{CH}$ buildings in Iloilo city, Philippines. Background imagery by (C) 2019 CNES/Airbus, Maxar Technologies; map data by (C) 2019 Google.

years are dated around the beginning of the last century; however, during their operational life, the Iloilo City $\mathrm{CH}$ assets have experienced catastrophic events (e.g. earthquake and fire) which have led to their partial or total reconstruction. As discussed above, new technologies have been used during the fieldwork in order to help the surveyors in the data collection exercise. In particular, drones have been extensively used for façade and roof inspections. As an example, Fig. 6a shows the façade of the Villanueva building (ICCHCC, 2010), while Fig. $6 \mathrm{~b}$ shows the building roof. The Villanueva building is an L-shaped, two-storey RC frame, whose roof was inaccessible; the drone was the only practicable tool for collecting roof data and information. The only limitation on the use of drones was the strong wind during the fieldwork, which strongly affected the flight capability. This important aspect must be considered when a survey campaign has to be organised in a cyclonic region. Figure $6 \mathrm{c}$ and d show the Villanueva building 6 (ICCHCC, 2010) façade and its point cloud respectively obtained by elaborating the pictures taken by smartphone and photo camera. Photogrammetry is a pow- 

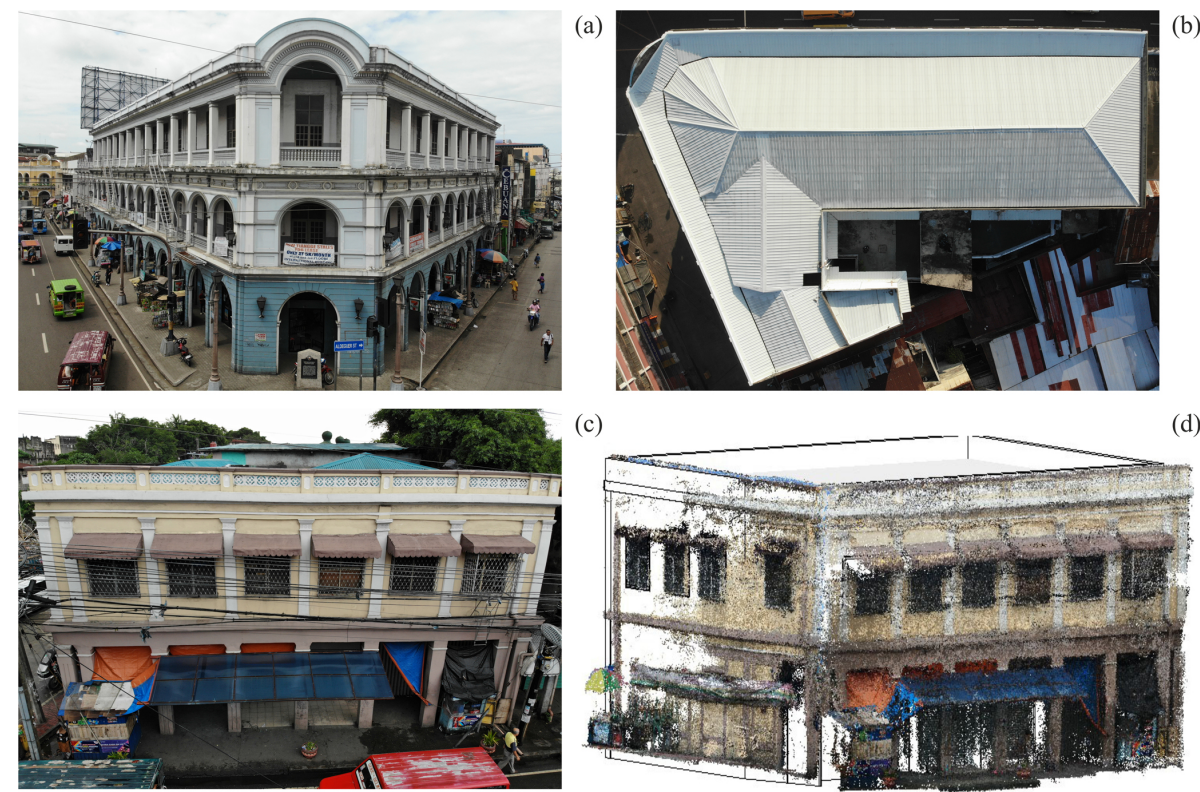

Figure 6. Use of new technologies for the survey of the Iloilo City $\mathrm{CH}$ assets: Villanueva building front façade (a), and roof (b) by drone; Villanueva building 6 front façade (c) and point cloud (d) by drone and photogrammetry respectively.

erful tool for the construction of point clouds, but specific practical rules must be followed to obtain good-quality results. This technology requires high-quality pictures of the façades with specific overlaps, according to the software used during the elaboration step. A good-quality point cloud can be obtained only if the façade is clear enough of obstacles, such as cars and people. This aspect must be considered during the planning phase of the survey campaign. Ideally, the pictures needed for photogrammetry should be taken during the hours in which there is less traffic, usually early morning.

\subsection{Main statistics of the data collected during the fieldwork}

The main statistics derived from the data collected during the fieldwork are reported in Fig. 7. Most of the surveyed $\mathrm{CH}$ assets are two-storey, regular-plan buildings, somehow justifying their good performance during the M 7.8 1948 Lady Caycay earthquake, the second-largest event in the 500-year recorded history of Philippine seismic activities (Geoscience Australia, 2012). The surveyed buildings are located within a complex urban context; in fact, they are parts of blocks with different shapes and compositions, thus complicating the estimation of their seismic vulnerability. The statistics of the structural condition parameter highlight the level of degradation and the lack of maintenance of the assets under investigation. Specifically, $60 \%$ of the surveyed buildings show structural conditions which moderately affect the building performance. This means deficiencies are present which may moderately affect the structural performance, such as small cracks concentrated on a limited number of structural ele- ments and infill panels and/or limited damage of the roof, whereas $36 \%$ of the considered assets shows structural conditions which may significantly affect the building performance, such as widespread cracks on structural elements, concrete cover crushing with rusty rebar and extended damage of the roof. Most of the structural deficiencies are due to the poor quality of the construction materials. The unusually large dimension of the aggregates together with an extreme heterogeneity in their distribution within the structural elements are the main causes of the bad performance of the materials.

Figure 7 shows a widespread presence of various vulnerability factors. The most common and dangerous vulnerabilities are the potential for pounding and the presence of short columns. This can be explained by the use of obsolete codes during the design and construction of these assets. Moreover, regarding the potential for pounding, the high annual population growth rate in Iloilo City has led to construction in all the available space, without concern for the distance between buildings. According to Fig. 7, various typologies of roof made by different construction materials can be found. Flat roofs are mainly made by concrete, while gable and monoand multi-pitch ones are generally characterised by a timber structure and metal roof sheets. An advanced degradation level affects the elements of the roofs, the structure and also the connections, i.e. fasteners and roof-to-wall connections, thus further increasing their vulnerability. 

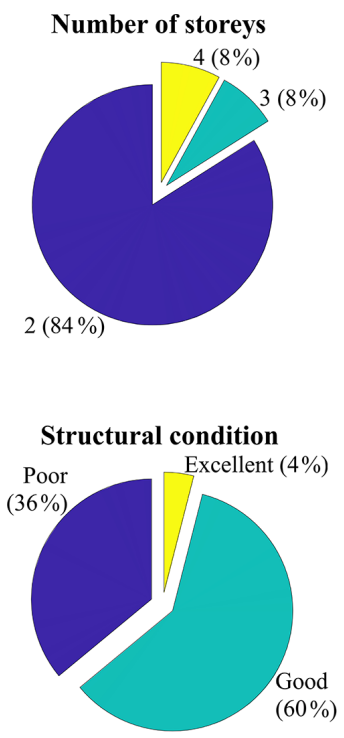
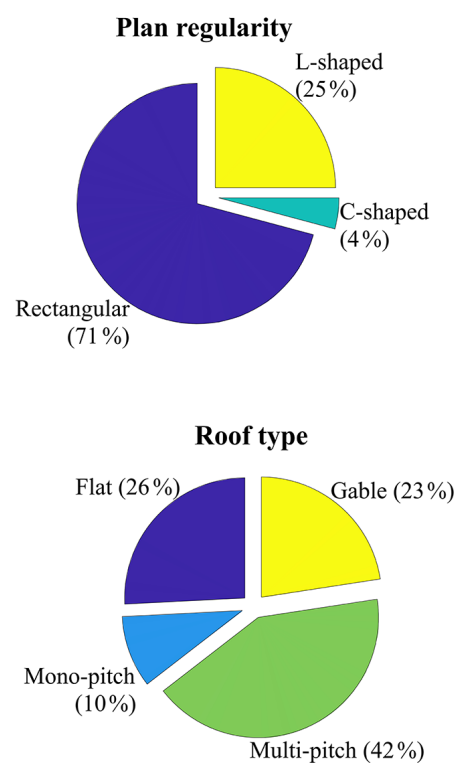
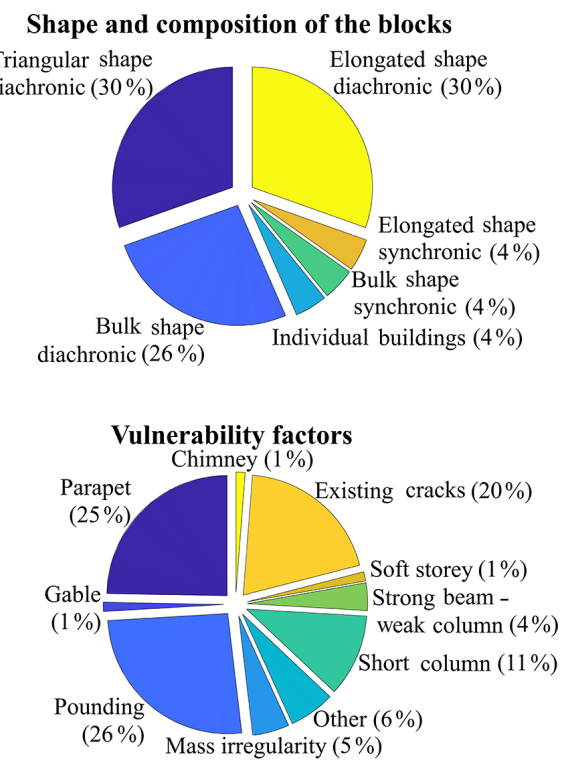

Figure 7. Statistics for the 25 surveyed $\mathrm{CH}$ buildings, Iloilo City, Philippines.

\subsection{Prioritisation scheme}

The collected data were finally used for the calculation of the risk prioritisation indices proposed in this study (Sect. 3). The resulting indices are arbitrarily categorised into three groups with green, yellow and red tags by defining two thresholds. The definition of such thresholds is essentially a subjective (often political) choice that shapes the prioritisation scheme, based for instance on resources availability. For a governmental agency, those can be calibrated by estimating the average structural retrofit (or relocation) cost per building and defining the amount of available public funding in two or more time windows (e.g. 1 and 5 years) to obtain specified DRR objectives. As a proof of concept, in this paper the thresholds are selected to be equal to $33 \%$ and $66 \%$ for the calculated seismic, wind or multi-hazard indices.

The seismic-risk prioritisation indices (Fig. 8a) show fairly homogeneous baseline scores, indicated with grey bars. This is due to the common construction features of the analysed $\mathrm{CH}$ assets. In fact, most of them are regular RC-frame structures built before the 1970s, and so they are considered pre-code structures. Figure 8a also highlights how important the performance modifiers, and so the vulnerability factors, are in the definition of the seismic prioritisation scheme. The analysed $\mathrm{CH}$ assets have common vulnerability factors, in particular pounding, and diffused degradation. These increase the values of the seismic-risk prioritisation indices, in fact only four assets are below the 33rd percentile. This also leads to a relatively small variability in the results. Due to relatively small extension of the survey area, the same unfavourable soil condition is assumed for all $\mathrm{CH}$ assets (Table 3).
The wind-risk prioritisation indices (Fig. 8c) show a higher variability when compared with the seismic ones. This is mainly due to the different construction features and degradation conditions of $\mathrm{CH}$-asset roofs observed during the survey. Highly degraded roofs are strongly penalised by the scores considered in this study (Table 5). Therefore, structures with the worst maintenance conditions show the highest values of the wind-risk prioritisation indices. In this study, all of the $\mathrm{CH}$ assets are considered to be located in the same hazard region (medium hazard, Table 6).

The two indices are finally combined following the procedure proposed in Sect. 3.4, thus obtaining the multi-hazard prioritisation indices $\left(I_{\text {multi }}\right)$ shown in Fig. 8e. The results clearly indicate that the wind hazard plays a substantial role in determining the prioritisation scheme for the $\mathrm{CH}$ assets in Iloilo city. Indeed, the overall trend of the multi-hazard results is practically the same as that of the wind indices.

Finally, the intangible value of $\mathrm{CH}$ assets is considered in the definition of the prioritisation scheme according to the procedure proposed in Sect. 3.5. In order to assess the validity of the proposed procedure, the analysed $\mathrm{CH}$ assets are assumed to be characterised by local significance, except for the building 01-013, one of the assets which behaves better, whose significance is considered to be recognised at national level. Figure 9 shows the multi-hazard prioritisation indices which consider the intangible value of $\mathrm{CH}$. The general trend is the same as that of the wind prioritisation index, but the relative position of building 01-013 changes. This simple example shows that, if the intangible value of $\mathrm{CH}$ assets within a given portfolio is not homogeneous, it can drive the prioritisation scheme. 

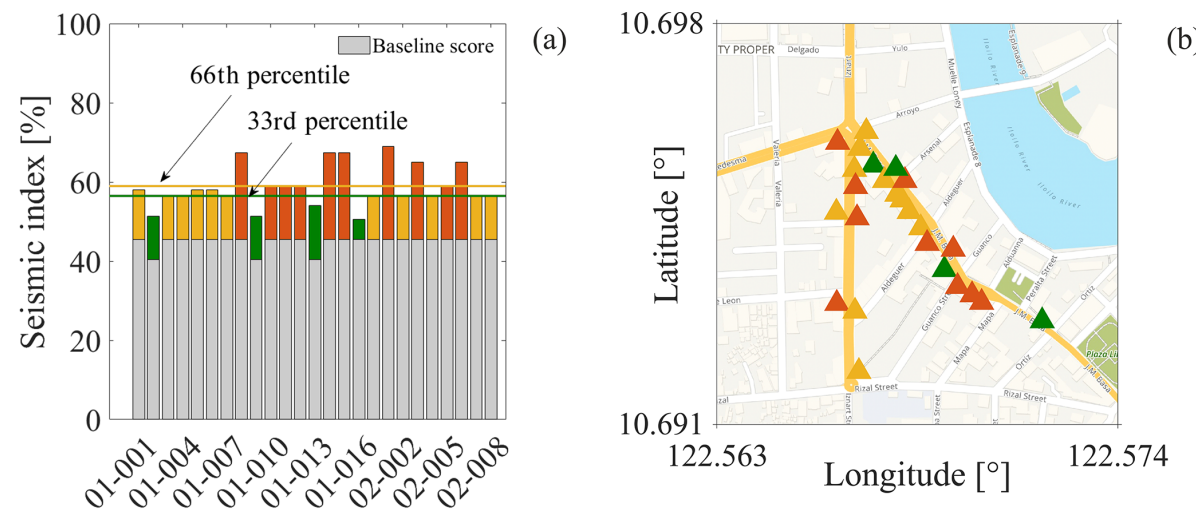

(b)

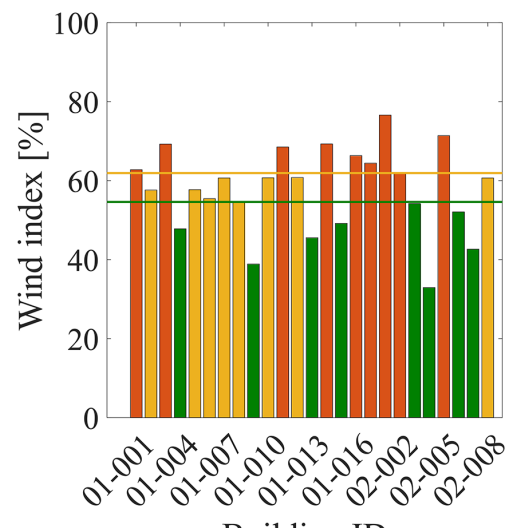

(c)

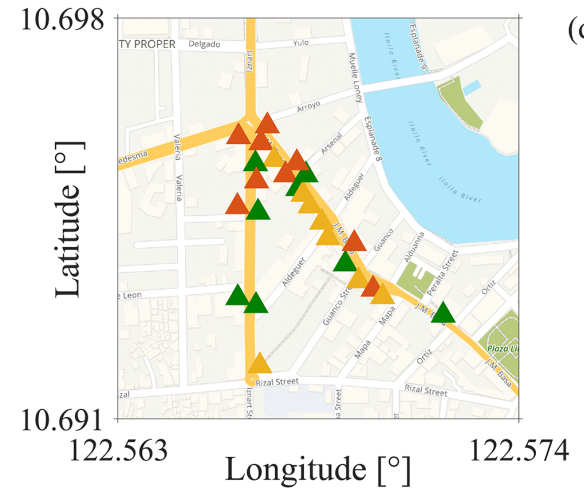

(d)

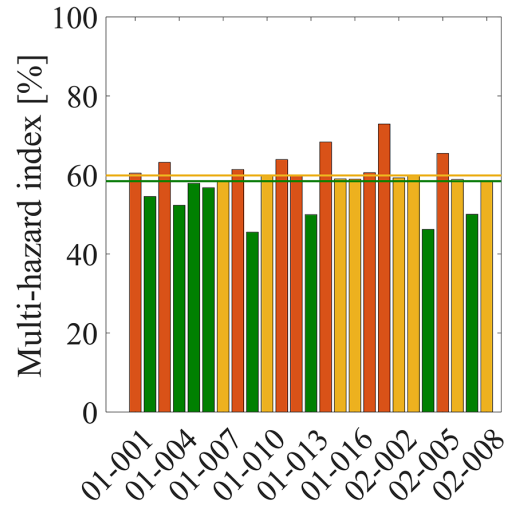

(e)

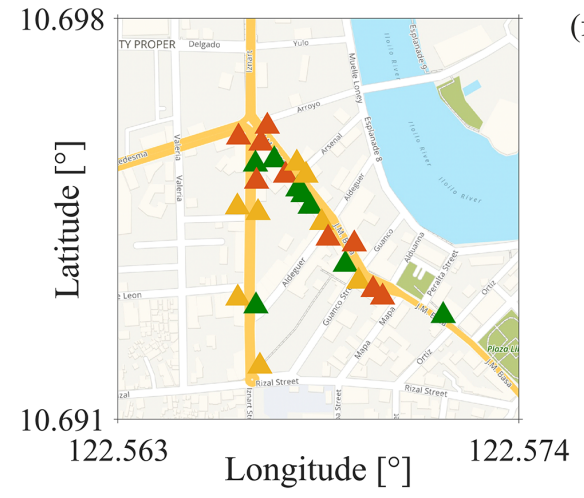

Building ID

Figure 8. Prioritisation indices: (a) seismic-risk prioritisation index; (c) wind-risk prioritisation index; (e) multi-hazard risk prioritisation index. Panels (b), (d) and (f) show the corresponding locations of buildings. Background map by () OpenStreetMap contributors, 2019. Distributed under a Creative Commons BY-SA Licence.

\section{Concluding remarks}

This paper presented a multi-hazard risk prioritisation framework for $\mathrm{CH}$ assets which represents the lowest refinement level of a multilevel risk and resilience assessment procedure. This procedure is indeed one of the first outcomes of the Cultural Heritage Resilience \& Sustainability to multiple Hazards (CHeRiSH) project, which aims to develop a multi- level, harmonised and engineering-based risk and resilience assessment framework for $\mathrm{CH}$ assets in the Philippines exposed to multiple natural hazards.

To this aim, an ad hoc RVS form designed for $\mathrm{CH}$ assets has been introduced in this paper. In particular, the multilevel architecture of the proposed RVS form allows one to improve the estimation of the structural fragility and risk once new detailed information is available. At the lowest refinement level 


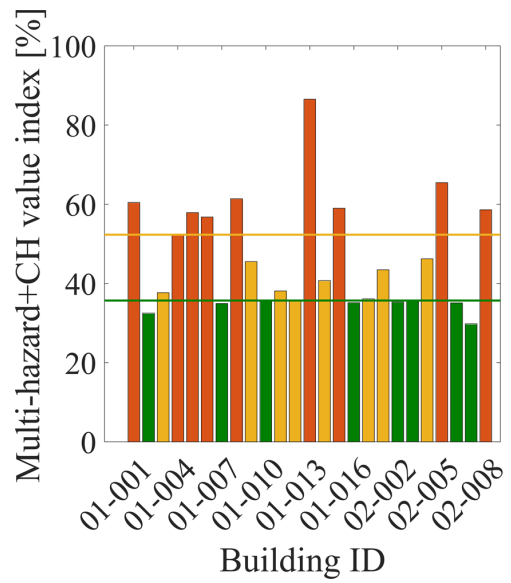

(a)

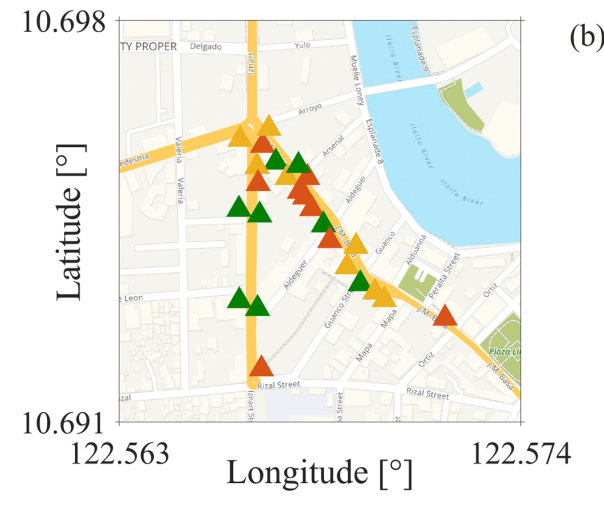

Figure 9. Multi-hazard risk prioritisation index which considers the intangible value of $\mathrm{CH}$. Background map by () OpenStreetMap contributors, 2019. Distributed under a Creative Commons BY-SA Licence.

(the main focus of the paper), the data gathered in the RVS form are used for the calculation of the proposed seismic and wind prioritisation indices. They represent empirical proxies for the relative risk of $\mathrm{CH}$ assets within the analysed portfolio, and they can be used only for prioritisation purposes.

The proposed seismic-risk prioritisation index extended the one developed within the INSPIRE project to the case of URM buildings. It consists of two parts: a baseline score and a performance modifier. The baseline score calculation is based on the HAZUS model fragility curves, while the performance modifier is computed as a weighted summation of scores related to macro-categories and secondary parameters, which, if present, are deemed to jeopardise the building performance. The macro-categories express the seismic failure chain peculiar to URM buildings. Each of them contributes to the calculation of the performance modifier through secondary parameters which express specific structural features which can prevent or promote the activation of failure mechanisms, as observed during post-earthquake surveys. The proposed wind-risk prioritisation index was similarly defined as the weighted summation of scores and weights related to vulnerability factors of $\mathrm{CH}$-asset roofs multiplied by a hazard parameter. The vulnerability factors defined within the SCOSSO project have been adapted in this work to the needs of $\mathrm{CH}$ assets. A simple method to combine risk prioritisation indices related to different hazards and which allows for the consideration of the intangible value of $\mathrm{CH}$ assets has been finally introduced. The multi-hazard risk prioritisation index was calculated as the Euclidian norm of the vector whose components are the single-hazard prioritisation indices. The intangible value of $\mathrm{CH}$ assets was considered by multiplying the multi-hazard risk prioritisation index by a score that accounts for the significance of the asset as $\mathrm{CH}$. The analytic hierarchy process (AHP) has been extensively used to calibrate combination weights and scores, thus reducing the subjectivity involved in the procedure.
The application of the proposed prioritisation framework on the $\mathrm{CH}$ assets of Iloilo City, Philippines, has shown its feasibility in practice. Findings from the fieldwork highlight the important role played by the widespread vulnerability factors, strongly affecting the performance of the surveyed $\mathrm{CH}$ assets. The case study highlighted the need to consider the intangible value of $\mathrm{CH}$ assets within prioritisation procedures.

This study represents a first step toward a comprehensive framework for multi-hazard risk assessment and optimal resilience-enhancing strategy selection for $\mathrm{CH}$ assets. Future developments will aim to improve the quantification of the wind vulnerability through the definition of suitable numerical models which consider degradation effects and climate change impact. 
Appendix A: Judgement matrices used in the analytic hierarchy process

Table A1. Judgement matrix adopted for the calibration of the macro-category weights.

\begin{tabular}{lrrrr}
\hline & $\begin{array}{r}\text { Material } \\
\text { quality }\end{array}$ & $\begin{array}{r}\text { Local } \\
\text { behaviour }\end{array}$ & $\begin{array}{r}\text { Global } \\
\text { behaviour }\end{array}$ & $\begin{array}{r}\text { Façade } \\
\text { ornaments }\end{array}$ \\
\hline Material quality & 1 & 2 & 3 & 5 \\
Local behaviour & $1 / 2$ & 1 & 2 & 5 \\
Global behaviour & $1 / 3$ & $1 / 2$ & 1 & 5 \\
Façade ornaments & $1 / 5$ & $1 / 5$ & $1 / 5$ & 1 \\
\hline
\end{tabular}

Table A2. Judgement matrix adopted for the calibration of the out-of-plane behaviour weights.

\begin{tabular}{lrrrrrrr}
\hline & $\begin{array}{r}\text { Opening } \\
\text { layout }\end{array}$ & $\begin{array}{r}\text { Wall } \\
\text { slenderness }\end{array}$ & $\begin{array}{r}\text { Opening } \\
\text { alignment }\end{array}$ & $\begin{array}{r}\text { Opening } \\
\text { area }\end{array}$ & $\begin{array}{r}\text { Wall-to-wall } \\
\text { connection }\end{array}$ & $\begin{array}{r}\text { Floor-to-wall } \\
\text { connection }\end{array}$ & $\begin{array}{r}\text { Wall-to-roof } \\
\text { connection }\end{array}$ \\
\hline Opening Layout & 1 & 2 & $1 /$ & 1 & $1 / 3$ & $1 / 6$ & $1 / 3$ \\
Wall slenderness & $1 / 2$ & 1 & $1 / 2$ & $1 / 2$ & $1 / 6$ & $1 / 8$ & $1 / 6$ \\
Opening alignment & 2 & 2 & 1 & 2 & $1 / 2$ & $1 / 3$ & $1 / 2$ \\
Opening area & 1 & 2 & $1 / 2$ & 1 & $1 / 6$ & $1 / 8$ & $1 / 3$ \\
Wall-to-wall connection & 3 & 6 & 2 & 6 & 3 & 1 & 1 \\
Floor-to-wall connection & 6 & 8 & 3 & 8 & 1 & $1 / 2$ & 1 \\
Wall-to-roof connection & 3 & 6 & 2 & 6 & & & $1 / 6$ \\
\hline
\end{tabular}

Table A3. Judgement matrix adopted for the calibration of the in-plane behaviour weights.

\begin{tabular}{lrrrrr}
\hline & $\begin{array}{r}\text { Plan } \\
\text { shape }\end{array}$ & $\begin{array}{r}\text { Storey } \\
\text { height } \\
\text { uniformity }\end{array}$ & $\begin{array}{r}\text { Added } \\
\text { storeys }\end{array}$ & Pounding & $\begin{array}{r}\text { Unfavourable } \\
\text { soil }\end{array}$ \\
\hline Plan shape & 1 & 2 & 2 & $1 / 2$ & $1 / 2$ \\
Storey height uniformity & $1 / 2$ & 1 & 1 & $1 / 4$ & 1 \\
Added storeys & $1 / 2$ & 1 & 1 & $1 / 3$ & $1 / 2$ \\
Pounding & 2 & 4 & 3 & 1 & 4 \\
Unfavourable soil & 2 & 1 & 2 & $1 / 4$ & 1 \\
\hline
\end{tabular}

Table A4. Judgement matrix adopted for the calibration of the RC-building weights.

\begin{tabular}{|c|c|c|c|c|c|c|c|c|}
\hline & $\begin{array}{r}\text { Preservation } \\
\text { condition }\end{array}$ & $\begin{array}{l}\text { Plan } \\
\text { shape }\end{array}$ & $\begin{array}{r}\text { Storey } \\
\text { height } \\
\text { uniformity }\end{array}$ & $\begin{array}{l}\text { Added } \\
\text { storeys }\end{array}$ & $\begin{array}{r}\text { Infills } \\
\text { at ground } \\
\text { storey }\end{array}$ & $\begin{array}{l}\text { Short } \\
\text { column }\end{array}$ & Pounding & $\begin{array}{r}\text { Unfavourable } \\
\text { soil }\end{array}$ \\
\hline Preservation condition & 1 & 1 & 2 & 2 & $1 / 3$ & $1 / 2$ & $1 / 2$ & 2 \\
\hline Plan shape & 1 & 1 & 2 & 2 & $1 / 3$ & $1 / 2$ & $1 / 2$ & $1 / 2$ \\
\hline Storey height uniformity & $1 / 2$ & $1 / 2$ & 1 & 1 & $1 / 6$ & $1 / 4$ & $1 / 4$ & 1 \\
\hline Added storeys & $1 / 2$ & $1 / 2$ & 1 & 1 & $1 / 6$ & $1 / 4$ & $1 / 4$ & 1 \\
\hline Infills at ground storey & 3 & 3 & 6 & 6 & 1 & 2 & 2 & 6 \\
\hline Short column & 2 & 2 & 4 & 4 & $1 / 2$ & 1 & 1 & 4 \\
\hline Pounding & 2 & 2 & 4 & 4 & $1 / 2$ & 1 & 1 & 4 \\
\hline Unfavourable soil & $1 / 2$ & 2 & 1 & 1 & $1 / 6$ & $1 / 4$ & $1 / 4$ & 1 \\
\hline
\end{tabular}


Table A5. Judgement matrix adopted for the calibration of the roof vulnerability factor weights.

\begin{tabular}{|c|c|c|c|c|c|c|c|c|}
\hline & $\begin{array}{l}\text { Code } \\
\text { level }\end{array}$ & $\begin{array}{r}\text { Number of } \\
\text { storeys }\end{array}$ & $\begin{array}{r}\text { Roof } \\
\text { structure }\end{array}$ & $\begin{array}{r}\text { Roof } \\
\text { covering }\end{array}$ & $\begin{array}{l}\text { Roof } \\
\text { pitch }\end{array}$ & $\begin{array}{r}\text { Roof } \\
\text { condition }\end{array}$ & $\begin{array}{r}\text { Roof } \\
\text { connection }\end{array}$ & $\begin{array}{l}\text { Structural } \\
\text { condition }\end{array}$ \\
\hline Code level & 1 & 3 & 2 & 2 & 2 & 1 & 1 & 1 \\
\hline Number of storeys & $1 / 3$ & 1 & $1 / 2$ & $1 / 2$ & $1 / 2$ & $1 / 4$ & $1 / 4$ & $1 / 4$ \\
\hline Roof structure & $1 / 2$ & 2 & 1 & 1 & 1 & $1 / 2$ & $1 / 2$ & $1 / 2$ \\
\hline Roof covering & $1 / 2$ & 2 & 1 & 1 & 1 & $1 / 4$ & $1 / 4$ & $1 / 4$ \\
\hline Roof pitch & $1 / 2$ & 2 & 1 & 1 & 1 & $1 / 2$ & $1 / 2$ & 1 \\
\hline Roof condition & 1 & 4 & 2 & 4 & 2 & 1 & $1 / 2$ & 1 \\
\hline Roof connection & 1 & 4 & 2 & 4 & 2 & 2 & 1 & 1 \\
\hline Structural condition & 1 & 4 & 2 & 4 & 1 & 1 & 1 & 1 \\
\hline
\end{tabular}

Table A6. Judgement matrix adopted for the calibration of the hazard parameters.

\begin{tabular}{lrrr}
\hline & $\begin{array}{r}\text { High } \\
\text { wind } \\
\text { hazard }\end{array}$ & $\begin{array}{r}\text { Medium } \\
\text { wind } \\
\text { hazard }\end{array}$ & $\begin{array}{r}\text { Low } \\
\text { wind } \\
\text { hazard }\end{array}$ \\
\hline High wind hazard & 1 & 2 & 3 \\
Medium wind hazard & $1 / 2$ & 1 & 2 \\
Low wind hazard & $1 / 3$ & $1 / 2$ & 1 \\
\hline
\end{tabular}

Table A7. Judgement matrix adopted for the calibration of the $\mathrm{CH}$ value scores.

\begin{tabular}{lrrrr}
\hline & $\begin{array}{c}\text { Exceptional } \\
\text { significance }\end{array}$ & $\begin{array}{r}\text { Considerable } \\
\text { significance }\end{array}$ & $\begin{array}{r}\text { Some } \\
\text { significance }\end{array}$ & $\begin{array}{r}\text { Little } \\
\text { significance }\end{array}$ \\
\hline Exceptional significance & 1 & 2 & 3 & 4 \\
Considerable significance & $1 / 2$ & 1 & 2 & 3 \\
Some significance & $1 / 3$ & $1 / 2$ & 1 & 2 \\
Little significance & $1 / 4$ & $1 / 3$ & $1 / 2$ & 1 \\
\hline
\end{tabular}


Data availability. Data will be made available on request.

Supplement. The supplement related to this article is available online at: https://doi.org/10.5194/nhess-20-1391-2020-supplement.

Author contributions. GS and CG conceived and designed the study, developed the proposed framework, and wrote the manuscript; GS performed the analyses; GS and RDJ collected the data with AO, MEDAG and RI supervising the data collection; DDA advised on the URM performance modifiers and literature review; all the authors discussed the results.

Competing interests. The authors declare that they have no conflict of interest.

Special issue statement. This article is part of the special issue "Groundbreaking technologies, big data, and innovation for disaster risk modelling and reduction". It is not associated with a conference.

Acknowledgements. This study was performed in the framework of the Cultural Heritage Resilience \& Sustainability to multiple Hazards (CHeRiSH) project funded by the British Council. The University of the Philippines Visayas (UPV); the Central Philippine University (CPU); and the De La Salle University (DLSU), Manila, are acknowledged for technical support during the fieldwork. The graduate students from CPU and Kieran O'Sullivan and Sabrina Di Stasio from University College London (UCL), who participated in the fieldwork, are also gratefully acknowledged. We thank the anonymous reviewer and Fulvio Parisi (University of Naples Federico II, Italy) for the very helpful comments that improved the quality of this paper. The authors are very grateful to Roberto Gentile at UCL for the discussion on his work and for sharing some of the scripts used to generate the figures in this paper.

Financial support. This research has been supported by the British Council (grant no. 414707017).

Review statement. This paper was edited by Rui Figueiredo and reviewed by Fulvio Parisi and one anonymous referee.

\section{References}

Aicardi, I., Chiabrando, F., Maria Lingua, A., and Noardo, F.: Recent trends in cultural heritage 3D survey: The photogrammetric computer vision approach, J. Cult. Herit., 32, 257-266, https://doi.org/10.1016/j.culher.2017.11.006, 2018.

Association of structural engineers of the Philippines: National Structural Code of the Philippines, Manila, Philippines, 2015.
Borri, A., Corradi, M., Castori, G., and De Maria, A.: A method for the analysis and classification of historic masonry, Bull. Earthq. Eng., 13, 2647-2665, https://doi.org/10.1007/s10518-015-97314, 2015.

Brzev, S., Scawthorn, C., Charleson, A. W., Allen, L., Greene, M., Jaiswal, K., and Silva, V.: GEM Building Taxonomy Version 2.0, GEM Technical Report, GEM foundation, Pavia, Italy, 2013.

Croce, P., Landi, F., and Formichi, P.: Probabilistic Seismic Assessment of Existing Masonry Buildings, Buildings, 9, 237, https://doi.org/10.3390/buildings9120237, 2019.

D'Ayala, D.: Force and displacement based vulnerability assessment for traditional buildings, Bull. Earthq. Eng., 3, 235-265, https://doi.org/10.1007/s10518-005-1239-x, 2005.

D'Ayala, D.: Assessing the seismic vulnerability of masonry buildings, in: Handbook of seismic risk analysis and management of civil infrastructure systems, edited by: Tesfamariam, S. and Goda, K., Woodhead Publishing, Elsevier, USA, 334-365, 2013.

D'Ayala, D.: Conservation principles and performance based strengthening of heritage buildings in post-event reconstruction, in: Perspectives on European Earthquake Engineering and Seismology, Geotechnical, Geological and Earthquake Engineering, vol. 34, edited by: Ansal, A., Springer, Cham, 2014.

D'Ayala, D. and Speranza, E.: Definition of Collapse Mechanisms and Seismic Vulnerability of Historic Masonry Buildings, Earthq. Spectra, 19, 479-509, https://doi.org/10.1193/1.1599896, 2003.

D’Ayala, D., Wang, H., and Copping, A.: A Conceptual Model for Multi-Hazard Assessment of the Vulnerability of Historic Buildings, in: Procedings of the 5th International Conference in Structural Analysis of Historical Constructions. Posibilities of Number and Experimental Techniques, 6-8 November 2006, New Deli, India, 2006.

D’Ayala, D., Galasso, C., Nassirpour, A., Adhikari, R., Yamin, L., Fernández, R., Lo, D., Garciano, L., and Oreta, A.: Resilient communities through safer schools, Int. J. Disast. Risk Reduct., 45, 101446, https://doi.org/10.1016/j.ijdrr.2019.101446, 2020.

D’Ayala, D., Galasso, C., Putrino, V., Fanciullacci, D., Barucco, P., Fanciullacci, V., Bronzino, C., Zerrudo, E., Manalo, M., Fradiquela, C., Regalado, J., Garciano, L., Oreta, A., and Yu, K.: Assessment of the Multi-Hazard Vulnerability of Priority Cultural Heritage Structures in the Philippines, in: Proceedings of ICONHIC 2016 1st International Conference on Natural Hazards \& Infrastructure, 28-30 June 2016, Chania, Greece, 2016.

De Luca, F., Woods, G., Galasso, C., and D'Ayala, D.: RC infilled building performance against the evidence of the 2016 EEFIT Central Italy post-earthquake reconnaissance mission: empirical fragilities and comparison with the FAST method, Bull. Earthq. Eng., 16, 2943-2969, https://doi.org/10.1007/s10518-017-0289$1,2018$.

Despotaki, V., Silva, V., Lagomarsino, S., Pavlova, I., and Torres, J.: Evaluation of Seismic Risk on UNESCO Cultural Heritage sites in Europe, Int. J. Architect. Herit., 12, 1231-1244, https://doi.org/10.1080/15583058.2018.1503374, 2018.

European Commission: Safeguarding Cultural Heritage from Natural and Man-Made Disasters - A comparative analysis of risk management in the EU, Publications Office of the European Union, Luxembourg, 2018.

FEMA - Federal Emergency Management Agency: FEMA-155: Rapid Visual Screening of Buildings for Potential Seismic Haz- 
ards: Supporting Documentation, Federal Emergency Management Agency, Washington, D.C., USA, 2015a.

FEMA - Federal Emergency Management Agency: FEMA P-154: Rapid visual screening of buildings for potential seismic hazards: A Handbook, 3rd edn., Applied Technological Council (ATC), Washington, D.C., USA, 2015b.

Figueiredo, R., Romão, X., and Paupério, E.: Flood risk assessment of cultural heritage at large spatial scales: Framework and application to mainland Portugal, J. Cult. Herit., https://doi.org/10.1016/j.culher.2019.11.007, in press, 2019.

Filipino Republic Act No. 10066: National Cultural Heritage Act of 2009, Manila, Philippines, 2009.

Fiorentino, G., Forte, A., Pagano, E., Sabetta, F., Baggio, C., Lavorato, D., Nuti, C., and Santini, S.: Damage patterns in the town of Amatrice after August 24th 2016 Central Italy earthquakes, Bull. Earthq. Eng., 16, 1399-1423, https://doi.org/10.1007/s10518017-0254-z, 2018.

Fleming, K., Parolai, S., Garcia-Aristizabal, A., Tyagunov, S., Vorogushyn, S., Kreibich, H., and Mahlke, H.: Harmonizing and comparing single-type natural hazard risk estimations, Ann. Geophys., 59, S0216, https://doi.org/10.4401/ag-6987, 2016.

Gentile, R., Galasso, C., Idris, Y., Rusydy, I., and Meilianda, E.: From rapid visual survey to multi-hazard risk prioritisation and numerical fragility of school buildings, Nat. Hazards Earth Syst. Sci., 19, 1365-1386, https://doi.org/10.5194/nhess19-1365-2019, 2019.

Geoscience Australia: Strengthening Natural Hazard Risk Assessment Capacity in the Philippines: An Earthquake Impact Pilot Study for Iloilo City, Western Visayas, Canberra, 2012.

Heyman, J.: The stone skeleton: Structural engineering of masonry architecture, Cambridge University Press, Cambridge, https://doi.org/10.1017/CBO9781107050310, 1997.

ICBO - International Conference of Buildings Officials: Uniform Building Code, Whittier, California, USA, 1994.

ICCHCC: Implementing Rules and Regulations for the Downtown Central Business District (CBD) Heritage Zone, Iloilo City Cultural Heritage Conservation Council Report, Iloilo City, Philippines, 2010 .

Kerr, J. S.: The Conservation Plan: A Guide to the Preparation of Conservation Plans for Places of European Cultural Significance, 7th Edn., Australia ICOMOS Inc., Sidney, 2013.

Kircher, C. A., Whitman, R. V., and Holmes, W. T.: HAZUS Earthquake Loss Estimation Methods, Nat. Hazards Rev., 7, 45-59, https://doi.org/10.1061/(asce)1527-6988(2006)7:2(45), 2006.

Lagomarsino, S.: On the vulnerability assessment of monumental buildings, Bull. Earthq. Eng., 4, 445-463, https://doi.org/10.1007/s10518-006-9025-y, 2006.

Lagomarsino, S. and Giovinazzi, S.: Macroseismic and mechanical models for the vulnerability and damage assessment of current buildings, Bull. Earthq. Eng., 4, 415-443, https://doi.org/10.1007/s10518-006-9024-z, 2006.

Lagomarsino, S., Penna, A., Galasco, A., and Cattari, S.: TREMURI program: An equivalent frame model for the nonlinear seismic analysis of masonry buildings, Eng. Struct., 56, 1787-1799, https://doi.org/10.1016/j.engstruct.2013.08.002, 2013.

Mazzoni, S., Castori, G., Galasso, C., Calvi, P., Dreyer, R., Fischer, E., Fulco, A., Sorrentino, L., Wilson, J., Penna, A., and Magenes, G.: 2016-17 Central Italy Earthquake Sequence Seis- mic Retrofit Policy and Effectiveness, Earthq. Spectra, 34, 16711691, https://doi.org/10.1193/100717EQS197M, 2018.

Moratti, M., Gaia, F., Martini, S., Tsioli, C., Grecchi, G., Casotto, C., Calvi, G. M., Hertog, D. D., Calvi, P. M., and Proestos, G. T.: A methodology for the seismic multilevel assessment of unreinforced masonry church inventories in the Groningen area, Bull. Earthq. Eng., 17, 4625-4650, https://doi.org/10.1007/s10518019-00575-7, 2019.

Novelli, V.I., D’Ayala, D., Makhloufi, N., Benouar, D., and Zekagh, A.: A procedure for the identification of the seismic vulnerability at territorial scale. Application to the Casbah of Algiers, Bull. Earthq. Eng., 13, 177-202, https://doi.org/10.1007/s10518-0149666-1, 2015.

NSCP: Association of Structural Engineers of the Philippines, 2015.

Pagani, M., Garcia-Pelaez, J., Gee, R., Johnson, K., Poggi, V., Styron, R., Weatherill, G., Simionato, M., Viganò, D., Danciu, L., and Monelli D.: Global Earthquake Model (GEM) Seismic Hazard Map (version 2018.1 - December 2018), GEM foundation, Pavia, Italy, https://doi.org/10.13117/GEM-GLOBALSEISMIC-HAZARD-MAP-2018.1, 2018.

Parisi, F. and Augenti, N.: Seismic capacity of irregular unreinforced masonry walls with openings, J. Earthq. Eng. Struct. Dynam., 42, 101-121, 2013.

Paulay, T. and Priestley, M. J. N.: Seismic Design of Reinforced Concrete and Masonry Buildings, Wiley, ISBN 978-0471-54915-4, https://doi.org/10.1002/9780470172841, 1992.

Philippine Statistics Authority: Census of Population 2015: "Region VI (Western Visayas)", Total Population by Province, City, Municipality and Barangay, Report 2016-070, Manila, Philippines, 2016.

Philippine Statistics Authority: Contribution of Tourism to the Philippine Economy, Report 2019-093, Manila, Philippines, 2019.

Romão, X. and Paupério, E.: An Indicator for Post-disaster Economic Loss Valuation of Impacts on Cultural Heritage, Int. J. Architect. Herit., https://doi.org/10.1080/15583058.2019.1643948, 2020.

Saaty, T. L.: The analytic hierarchy process: planning, in: Priority Setting, Resource Allocation, MacGraw-Hill, New York International Book Company, New York, 1980.

Sheehan, M.: Cattolica in national nat cat scheme for religious buildings in Italy, available at: https://www.reinsurancene.ws/cattolica-in-national-nat-catscheme-for-religious-buildings-in, last access: 18 July 2018.

Song, B., Galasso, C., and Garciano, L.: WARP ${ }^{2}$ : Wind Assessment of Roofs to Pullout \& Pullover for Priority Cultural Heritage Structures in the Philippines, in: 13th International Conference on Applications of Statistics and Probability in Civil Engineering (ICASP13), 26-30 May 2019, Seoul, South Korea, 2019.

Sorrentino, L., D'Ayala, D., de Felice, G., Griffith, M. C., Lagomarsino, S., and Magenes, G.: Review of Out-ofPlane Seismic Assessment Techniques Applied To Existing Masonry Buildings, Int. J. Architect. Herit., 11, 2-21, https://doi.org/10.1080/15583058.2016.1237586, 2017.

Stephenson, V. and D'Ayala, D.: A new approach to flood vulnerability assessment for historic buildings in England, Nat. Hazards Earth Syst. Sci., 14, 1035-1048, https://doi.org/10.5194/nhess14-1035-2014, 2014. 
SWD - Commission Staff Working Document: 205/F2: Action Plan on the Sendai Framework for Disaster Risk Reduction 20152030, A disaster risk-informed approach for all EU policies, Brussels, Belgium, 2016.

UNESCO - United Nations Educational Scientific and Cultural Organization: Reducing Disaster Risk at World Heritage Properties, available at: https://whc.unesco.org/en/disaster-risk-reduction/, last access: 25 November 2008.

UNISDR - United Nations Office for Disaster Risk Reduction: Sendai Framework for Disaster Risk Reduction 2015-2030, Geneva, Switzerland, 2015.

Uva, G., Sanjust, C. A., Casolo, S., and Mezzina, M.: ANTAEUS Project for the Regional Vulnerability Assessment of the Current Building Stock in Historical Centers, Int. J. Architect. Herit., 10, 20-43, https://doi.org/10.1080/15583058.2014.935983, 2016.
Vecco, M.: A definition of cultural heritage: From the tangible to the intangible, J. Cult. Herit., 11, 321-324, 2010.

Vickery, P. J., Skerlj, P. F., Lin, J., Twisdale, L. A., Young, M. A., and Lavelle, F. M.: HAZUS-MH Hurricane Model Methodology. II: Damage and Loss Estimation, Nat. Hazards Rev., 7, 94-103, https://doi.org/10.1061/(asce)1527-6988(2006)7:2(94), 2006.

World Bank Group: Promoting Disaster Resilient Cultural Heritage, Report, 2017.

Yu, K. K. and Oreta, A. W.: Mulit-hazard risk and asset value assessment of heritage bildings (Case study in Iloilo City, Philippines), in: Proceedings of International Association for Bridge \& Structural Engineering (IABSE) Conference, 1315 May 2015, Nara, Japan, 2015. 